الخدمات الإرشادية الزراعية المقدمة من الجمعيات الأهلية للزراع في مجال التغيرات المناخية في محافظة

$$
\text { سلوى محمد عبد الجواد احمد }
$$

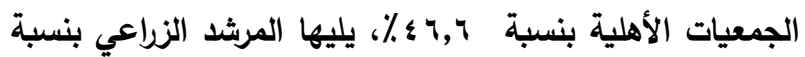
\% \& $\%, r$ الملخص العربى

وفيما يتعلق بالخدمات الإرشادية الزراعية المقدمة من

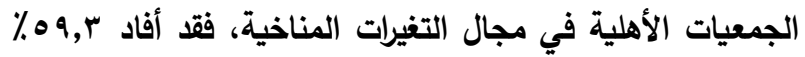
من المبحوثين بأن مستوى تلقيهم للخدمات متوسط، وكانت أكثر

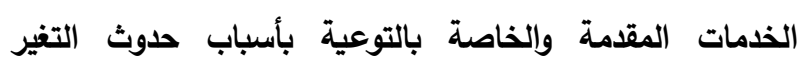
المناخي وآثاره السلبية هي: التوعية بعدم الأفراط في استخدام

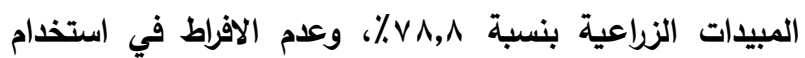

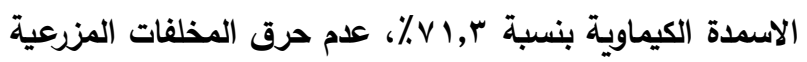

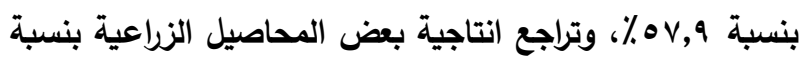

$$
\% 00, \xi
$$

وفيما يتعق بالظمات الإرشادية الخاصة بالحد من اثار

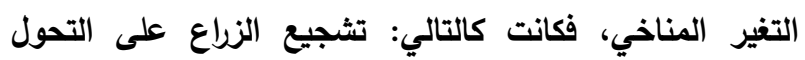

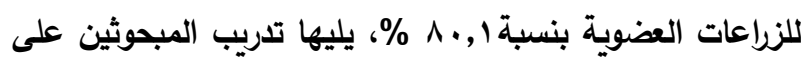

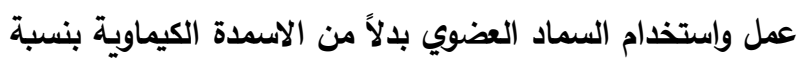

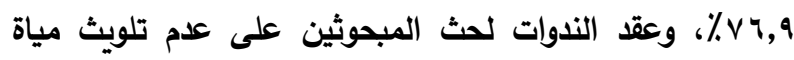

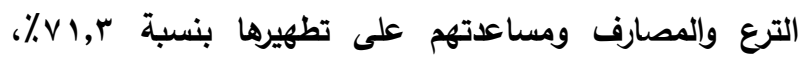

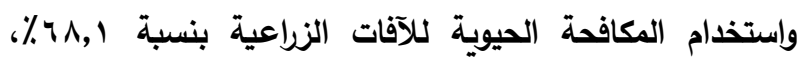

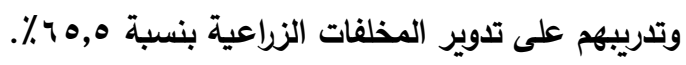
وكان مستوى استفادة المبحوثين من الخدمات والأنثطة

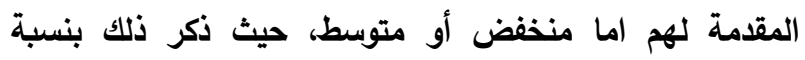

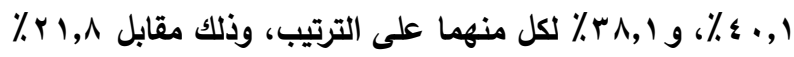

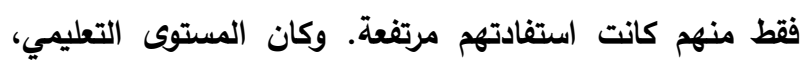

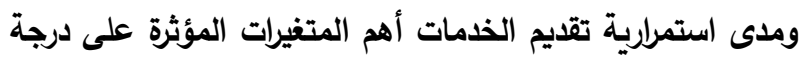

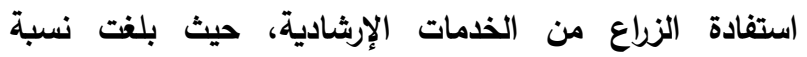

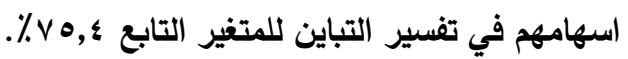
استهاف البحث التعرف على الخدمات الإثادية التي تقدمها المنظمات غير الحكومية (الجمعيات الأهلية العاملة في المجال

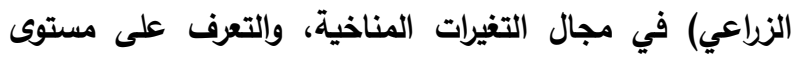
استفادة الزراع من تلك الخدمات، والتعرف على أهم مصادر التي يستقي منها المبحوثين معلوماتهم عن التغيرات المناخية، والتعرف على مدى استمرارية ومدى كفاية تقديم تلك الخدمات،

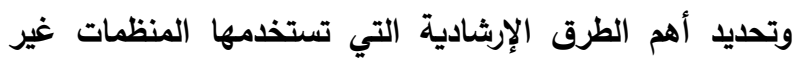

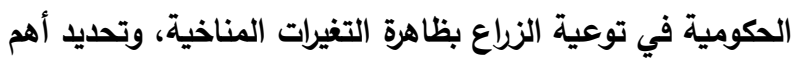
العوامل المؤثرة على مستوى استفادة الزراع من الخداعة الخدمات الإرشادية الزراعية المقدمة. وقد اجريت الدراسة في محافظة الفيوم، وتم اختيار عينة

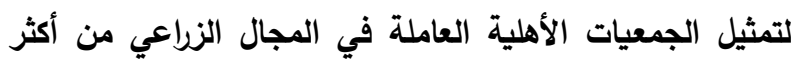

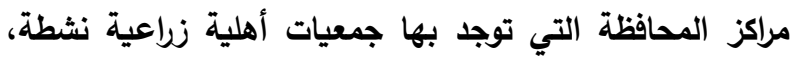
وهما مركزي الفيوم وطاميه، وتم اختيار قريتين من كل مركز، تركيل

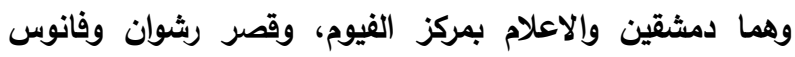
بمركز طاميه، وتم اخذ عينة عشوائية بسيطة من المستفيدين

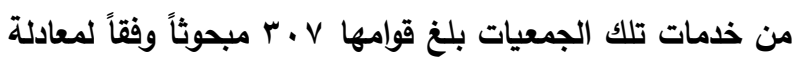
كرجسي ومورجان.

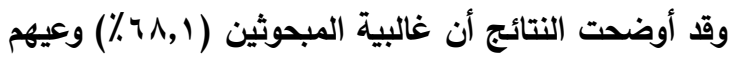

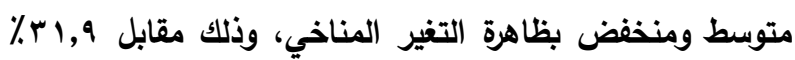

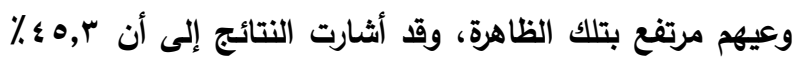
من المبحوثين تعرضهم متوسط لمصادر المعلومات وذلك مقابل ؛ 1\% فقط لذوى التعرض المرتفع، وقد تصدر تاجر مستلزمات

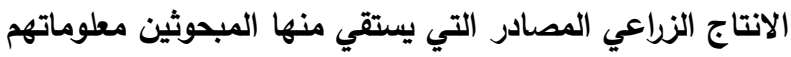

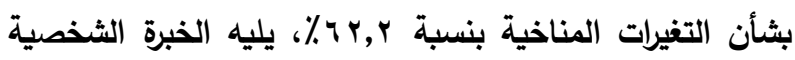

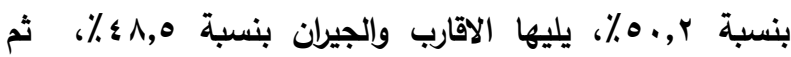

$$
\begin{aligned}
& \text { ' قسم الاقتصاد الزراعي - كلية الزراعة- جامعة الفيوم }
\end{aligned}
$$

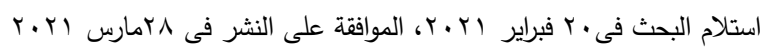


(p,7،2016)، ويتسبب الانتاج الحيواني بنحو ثلثي انبعاثات

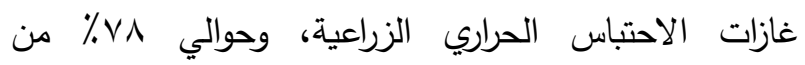
انبعاثات الميثان الزراعية، كما يولد الفاقد والمهدر من

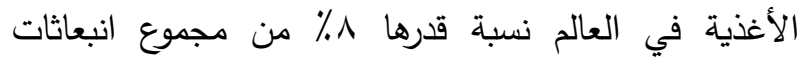

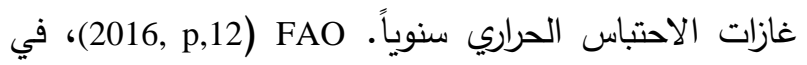

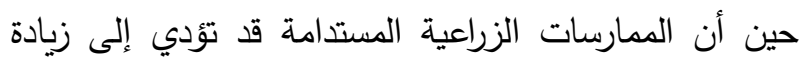
الإنتاجية والقدرة على الصمود والحد من حدة انبعاثات غازات

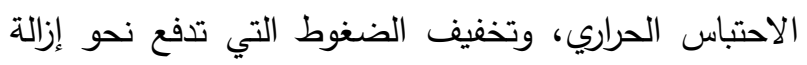
الغابات، وتحسين صحة التربة، والمناظر الطبيعية والغابات وهي كلها تؤدي إلى احتباس الكربون، ويمكن في كثير من الاحيان تحقيق الفوائد من جراء التخفيف من هذه الآثار وبدون تثبيط التمية الزراعية المستدامة.FAO (p,7،2016). ومن المتوقع أن تكون مصر احدى الدول الأكثر تضرراً من الآثار الناجمة عن تغير المناخ وتثكل هذه الآثار متمثلة

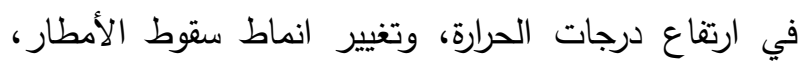

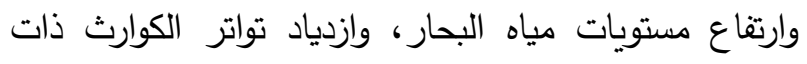

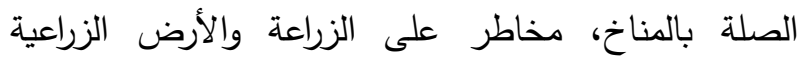

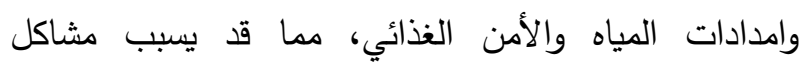

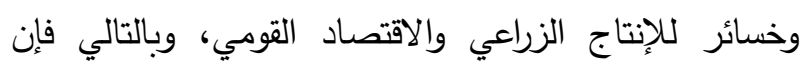

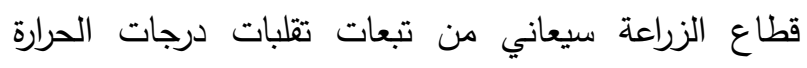
وسقوط الأمطار ويلحق به خسائر كبيرة. وذلك لأن الزراعة دئة المصرية تتواجد في بيئة شبه قاحلة وهثة، وتعتمد أساساً على مياه نهر النيل، وبالتالي سيكون قطاع الزراعة من اكثر

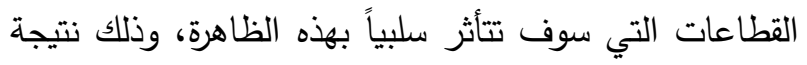
زيادة درجات الحرارة وتغير ترددات مواعيد الموجات الحرارية

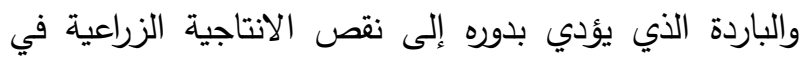

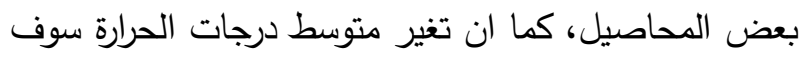

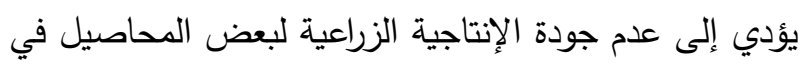

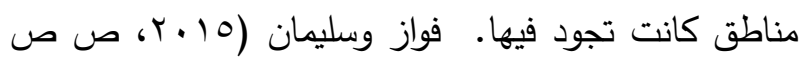
. (0. 1
الكلمات المفتاحية: التغير المناخي-المنظمات غير الحكومية-الخدمات الارشادية

\section{المقدمة والمثكلة البحثية}

يواجه العالم في الآونة الأخيرة مشكلة حقيقية ألا وهي التغيرات المناخية التي تتفاقم بإطراد وذلك نتيجة حرق التان

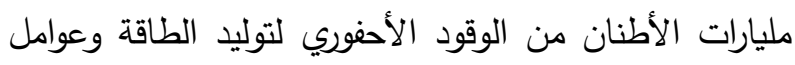

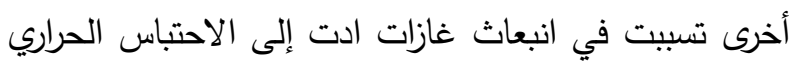

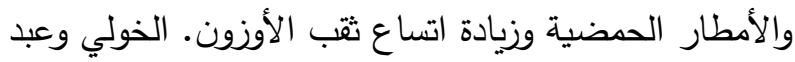

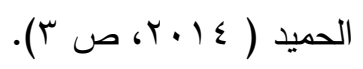

وتثكل التغيرات المناخية احدى أهم التهديدات أمام

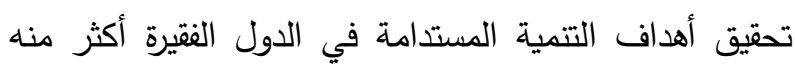

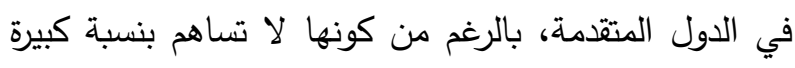

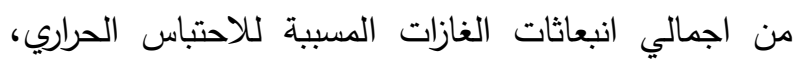
وذلك نظراً لما قد تسببه تلك الظاهرة من تأثيرات وتداعيات التاتيات مستقبلية خطيرة كجفاف بعض الأنهار وغرق اجزاء شاسعة من المناطق الساحلية، وتبدل خريطة مناطق الانتاج الزراعي

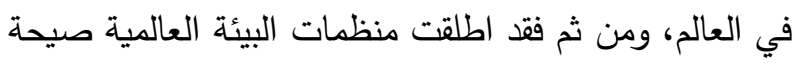
مدوية تحذر من تدهور المناخ العالمي. ندى عبد الظاهر

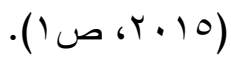

كما يطرح تغير المناخ تهديدا كبيرا ومتنامياً بالنسبة

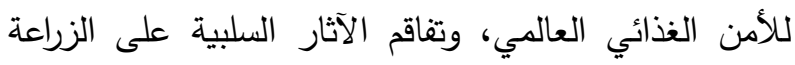
مما يجعل من الصعب تحقيق أهداف التتمية المستدامة الرئيسية المتمثلة في القضاء على الجوع، وتحقيق الأمن

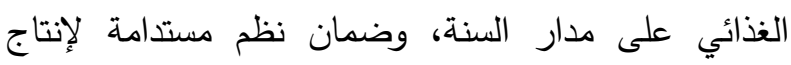

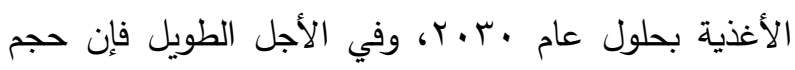

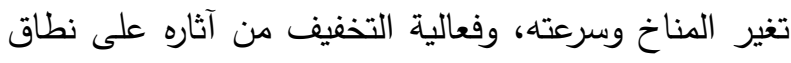

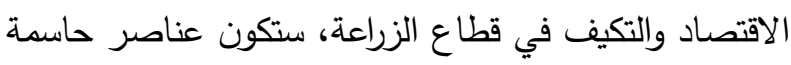
بالنسبة لمستقبل شرائح كبيرة من سكان العالم. FAO (2016،

وتتسبب القطاعات الزراعية في إنتاج نحو •r ب إلى

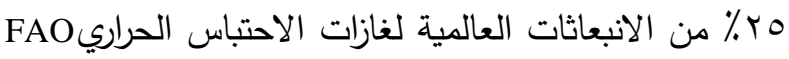


ان التخطيط السليم لمواجهة تلك الظاهرة وذلك بالتعاون الفاعل والقوي بين الجهات الحكومية وغير الحكومية من العوامل الهامة لبناء القدرة على مواجهة تغير المناخ، خاصة في ظل قصور خدمات القطاع الحكومي وما يعانيه من مشكلات خاصة بنقص الكوادر والتمويل وغيرها. فقد أثر تغير المناخ بالسلب على الزراع الذين تعودوا

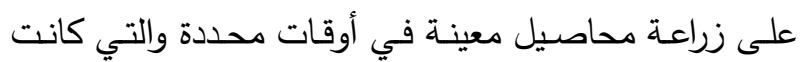

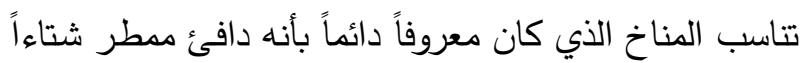
حار جاف صيفاً، ولكن مع التغيرات المناخية الحالية وتأثر لئر

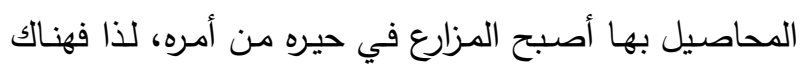
حاجة ماسة لرفع مستوى وعي الزراع بتلك الظاهرة، وذلك من

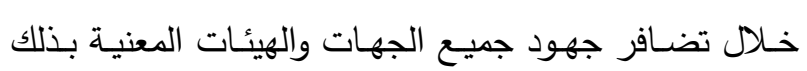
كالبحث العلمي وجهاز الإرشـاد الزراعي والمنظمسات غيـر الحكومية وخاصـة في ظل ما يعانيه جهاز الإرشاد الزراعى لإنى من قصور ومشكلات عديدة تعيق ادائه للدور المنوط به، وفي ظل التكامل بين جميع الجهات ذات الصلة المعنية بقضية التغيرات المناخية ولأهمية ما سبق فقد برزت الحاجة لإجراء تلك الدراسة للتعرف على أهم الخدمات الإرشادية المقدمة من المنظمات غير الحكومية العاملة في مجال الزراعة للزراع في منطقة البحث، وما هي الطرق الإرشادية التي تستخدمها هذه المنظمات في نقل المعلومات إلى المبحوثين لتوعيتهم بأهمية

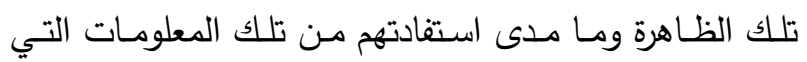
تقدمها تلك المنظمات ومدى استمرارية الخدمات المقدمة إليهم وأخيراً ما هي العوامل المؤثرة على مستوى استفادتهم من هذه الخدمات الإرشادية. أهداف الاراسة بناءاً على مشكلة الدراسة فقد تحددت أهدافها على النحو 1-التعرف على الخدمات الإرشادية الزراعية المقدمة من المنظمات غير الحكومية العاملة في المجال الزراعي في
وفي هذا الاتجاه ايضاً بينت بعض الدراسات التي إجريت عن التغيرات المناخية إنها سوف تؤدي إلى نقص إنتاجية بعض المحاصيل وتغير في النطاقات الزراعية، كذلك سوف تؤدي إلى انتشار الأمراض النباتية الفطرية والاصابات الحشرية المختلفة كاللفحة المتأخرة في الطماطم والبطاطس، وصدأ الساق والأوراق لمحصول القتح، كما من المتوقع ان ارتفاع درجات الحرارة يعمل على زيادة الاحتياج المائي للمحاصيل، بالإضافة إلى التأثير السلبي على الأراضي لئي الزراعية بالدلتا خاصة المناطق الثمالية المتاخمة لساحل

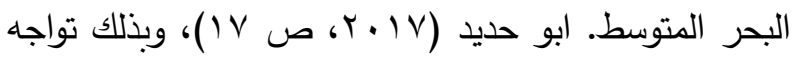
الزراعة المصرية تحدياً رئيسياً وهو توفير الغذاء الكافي لمواجهة الاحتياجات الاستهلاكية المتزايدة فضلاً عن الاسهام في النمو الاقتصادي والتشغيل وتوفير المواد الخام اللازمة للصناعات الزراعية والغذائية، ومما يزيد من خطورة هذا التحدي ما يشهده العالم من الآثار المعاكسة للتغيرات المناخية على الإنتاج الغذائي العالمي، وهو ما يؤثر سلباً على أوضاع الأمن الغذائي. الفران (ع ا ـ r، ص rمب). ومن هنا فإن التصدي للتحديات الجديدة التي تطرحها التغيرات المناخية يتطلب القيام بابتكارات زراعية خاصة

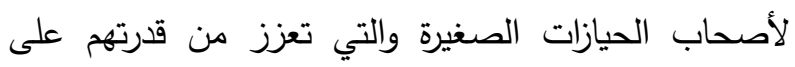
الصمود في مواجهة اثار تلك الظاهرة، كزيادة كفاءة استخدام الموارد وتكثيف الإنتاج الزراعي والادارة الفعالة لمياه الري، والاعتماد على التكنولوجيا الحيوية المنخفضة والعالية التكنولوجيا على حد السواء.

كذلك من الأهمية توافر تقنيات تطوير أصناف النباتات لتحقيق المرونة المناخية، وتقنيات توفير مياة الري وفقاً لمتطلبات الأمن المائي، كما أن هناك حاجة إلى نظم الانذار المبكر لمواجهة الحوادث المناخية، مما يساعد المزارعين على تقليل الخسائر المحتملة جراء حوادث العواصف لهف

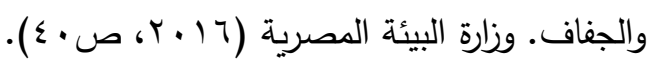


الاستعراض المرجعي: يتتاول هذا الجزء بعض المفاهيم

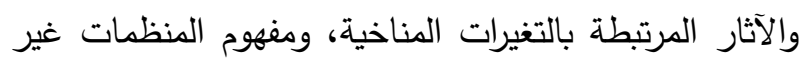
الحكومية، والادوار التي يمكن ان تقوم بها في مواجهة تلك الظاهرة، بالإضافة إلى الدراسات السابقة المتعلقة بمجال

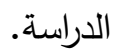

\section{أولاً: مفهوم التغيرات المناخية}

بدأ العالم منذ نهايات القرن العشرين يلاحظ خطورة الآثار المترتبطة على التغيرات المناخية على شتى مناحي الحياة سواء كانت اقتصادية أو صحية أو اجتماعية أو زراعية، ويعرف التغير المناخي climate change بأنه التغير

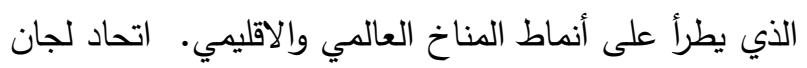

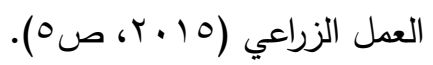

ويعني تغير المناخ "التغير الممكن تحديده "مثلاً عن طريق البحوث الاحصائية" من خلال متوسط التحولات وتباين خصائصها التي تستمر لحقبة زمنية طويلة عادة ما تتجاوز العقود، وتشمل هذه التحولات كل تغيير سواء بسبب التقلبات

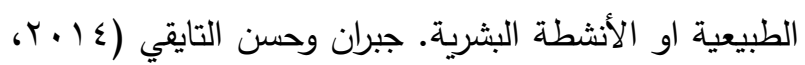

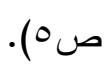

ويشير تغير المناخ إلى تغير طويل في متوسط نمط الطقس في منطقة معينة وخلال فترة زمنية طويلة، وينظر إليه أيضا على أنه تغيير في التوزيع الاحصائي لأنماط الطقس عندما يستمر هذا التغيير لفترة طويلة من الزمن. (2015, p226) Nwankwoala وينطوي تغير المناخ على تغيرات كبيرة على مدى عقود

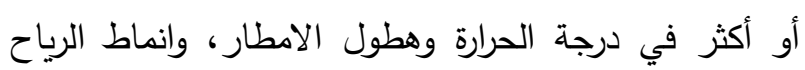
وجوانب اخرى من المناخ، ويتضمن تغير المناخ اتجاهات طويلة الأجل مثل التحول التدريجي نحو ظروف أكثر دفئًا أو وني رطوبة أوجفاف. EPA (2017,p1)

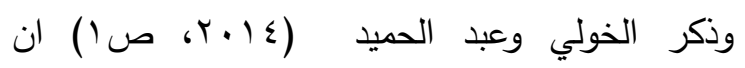
الاحتباس الحراري Global Warming هو ظاهرة ارتفاع
مجال التغيرات المناخية من وجهة نظر المبحوثين المستفيدين بتلك الخدمات. r-تحديد مستوى استفادة الزراع من الخدمات الإرشادية المقدمة من تلك المنظمات في مجال التغيرات المناخية. r-التعرف على اهم مصادر المعلومات الزراعية التي يستقي منها المبحوثين معلوماتهم عن ظاهرة التغير المناخي. ع-التعرف على مدى استمرارية الخدمات الإرشادية الزراعية المقدمة من تلك المنظمات، ومدى كفايتها من وجهة نظر

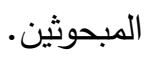

0-التعرف على أهم الطرق الإرشادية التي تستخدمها المنظمات غير الحكومية في توعية الزراع بظاهرة التغيرات

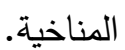
צ-تحديد أهم العوامل المؤثرة على مستوى استفادة الزراع من الخدمات الإرشادية المقدمة. الفروض النظرية: وفقاً لأهداف البحث تم صياغة

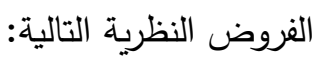

1- توجد علاقة ارتباطية معنوية بين المتغيرات المستقلة التالية: السن، والمستوى التعليمي، وحجم الحيازة الزراعية، وحجم الحيازة الحيوانية، والتفرغ للعمل الزراعي، ومستوى

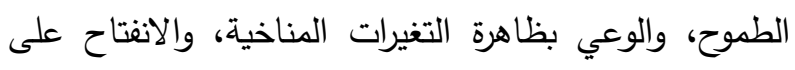
العالم الخارجي، والتعرض لمصادر المعلومات الزراعية، والاستفادة من مصادر المعلومات، واستمرارية الخدمات الإرشادية المقدمة، ومدي كفاية الخدمات المقدمة، وبين

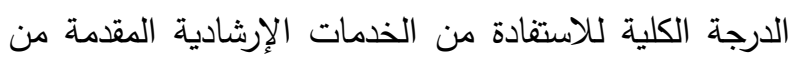
الجمعيات الأهلية للمبحوثين. ץ- يوجد تأثير معنوى للمتغيرات المستقلة السابقة على الدرجة الكلية للاستفادة من الخدمات الإرشادية الزراعية المقدمة للمبحوثين من قبل الجمعيات الأهلية. ويتم اختبار كل فرض من الفروض المشار اليها من خلال الفرض الاحصائي الذي ينص على عكس ذلك. 
وتعتبر المحاصيل والثروة الحيوانية والموارد الطبيعية عرضة لآثار تغير المناخ، وإن ضمان استدامة الإنتاج الزراعي والنظم الغذائية أمر أساسي لتحقيق أهداف متعددة بما في ذلك أهداف المناخ الوطنية والعالمية، وخطة التتمية المستدامة لعام •r.r.r، ويؤثر تغير المناخ على الانتاج

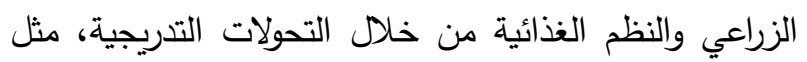
درجات الحرارة المرتفعة وتركيزات ثاني أكسيد الكربون في

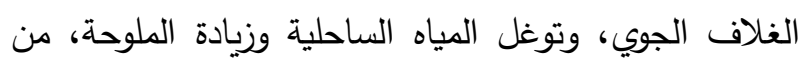
خلال زيادة تواتر وشدة الظواهر الجوية القصوى وكذلك من وندية ونياه

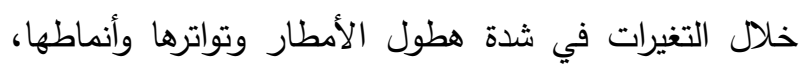
ويتسم انتاج المحاصيل بالحساسية الثديدة بالنسبة للمناخ، ويؤثر تغير المناخ على الغلة وجودة وتنوع العديد من أنواع المحاصيل في مناطق مختلفة وتتأثر انتاجية الثروه الحيوانية سلباً بتغير المناخ من خلال التأثيرات على التتوع البيولوجي للحيوان وصحته وتكاثره، ويؤثر تغير المناخ على تكوين غلة

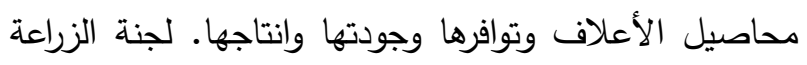

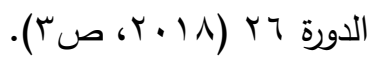

وهناك بعض الوسائل التي يمكن اتباعها للحد من

اسباب التغيرات المناخية المرتبطة بالزراعة والتي تتسبب في انبعاث غازات الاحتباس الحراي كاحتجاز الكربون في التربة الزراعية، عن طريق الادارة المستدامة للتربة وذلك من خلال

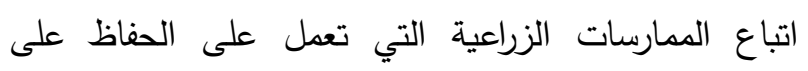
سلامة التربة وخصوبتها لخدمة الإنتاج الزراعي، كذلك الحد من انبعاثات غازات الاحتباس الحراري الناجمة عن قطاع الثروة الحيوانية، وأيضاً التخفيف من آثار انبعاثات أكسيد النيتروز ، حيث يتسرب النيتروجين بسهولة من التربة الزراعية

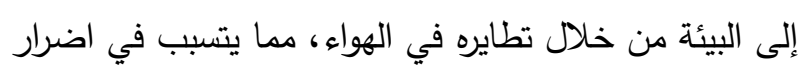
عديدة للبيئة، ويشكل ثاني اكسيد النيتروز غاز الاحتباس الحراري الذي يحتل المرتبة الثالثة من حيث الأهمية، ويمكن التغلب على ذلك من خلال الادارة المستدامة للنيتروجين في الزراعة من خلال اتباع الممارسات المحسنة. منظمة الأغذية
درجات الحرارة في بيئة ما نتيجة تدفق الطاقة الحرارية من البيئة وإليها.

ثانياً: أسباب حدوث التغيرات المناخية وأساليب الحد من آثار تلك الظاهرة

ينتج التغير المناخي عن العديد من العوامل، بما في ذلك إزالة الغابات، واستنفاد طبقة الأوزون، وزيادة ثاني أكسيد 2011, Sodangi I.A., et al الكربون في الغلاف الجوي. .(pp23:25)

ويحدث التغير المناخي نتيجة النشاط البشري الاقتصادي والذي يتسبب بإنتاج كميات هائلة من ثاني أكسيد الكربون والغازات الدفيئية الأخرى التي تتسبب في حبس لإنس الحرارة التي تمتصها الأرض من الثمس ومنعها من الانعكاس خارج الغلاف الجوي. اتحاد لجان العمل الزراعي

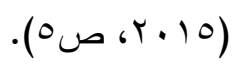

وقد ذكر أن التغيرات المناخية تحدث نتيجة ثلاثة أسباب أساسية وهي: غازات الاحتباس الحراري، حيث يعتقد أنها المساهم الرئيسي في حدوث تغير المناخ، كذلك فهنالك أسباب طبيعية، ناتجة عن الطبيعة وذلك حلك عن طريق انبعاثات ثاني أكسيد الكربون من البراكين، بالإضافة إلى المساهمات أوالأسباب الناتجة عن أنشطة البشر والتي تساهم في تغير المناخ، وذلك بالاعتماد على الوقود الاحفوري (البترول، الفحم) في سد الاحتياجات من الطاقة، والذي يترتب عليه زيادة غازات ثاني أكسيد الكربون والميثان وبعض الغازات الأخرى في الغلاف الجوى.

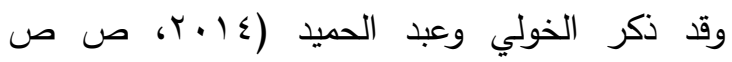
(Or،0) الحراري من خلال بعض الممارسات منها: ترشيد استخدام الطاقة والمياه، وتطوير العمليات الصناعية التي تستهدف هن ترن تقليل استهلاك الطاقة وخفض انبعاثات غازات الاحتباس ولطوير الحراري، واعادة تدوير المخلفات الصلبة الزراعية والصناعية، والبحث عن أنواع جديدة من الوقود. 
المستوى الوطني والأقليمي والدولي بشأن التغيرات في النظم الهيدرولوجية التي تؤثر على كمية الموارد المائية ونوعيتها،

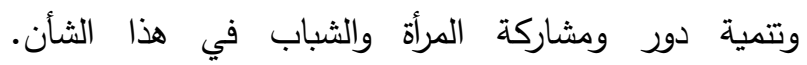
UNESCO (2017,p3) خامساً: الاراسات السابقة: يتتاول هذا الجزء عرضاً لنتائج بعض الدراسات والبحوث المرتبطة بمجال التغيرات المناخية، والتي يمكن عرضها على النحو التالي: دراسة قاسم (· ( • (Y)، استهدفت الدراسة التعرف على إدراك وأقلمة المزارعين لظاهرة التغير المناخي، وأظهرت

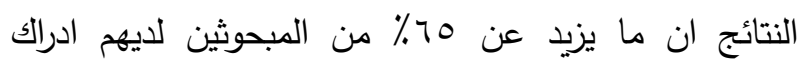
بظاهرة التغير المناخي، ويعد عدم توفير تمويل كافي من أكبر المعوقات التي تقابل المبحوثين للأقلمة مع التغير توفير المناخي، وان ما يزيد عن نصف المبحوثين لا يطبقون اي بديل من بدائل الأقلمة الواردة بالدراسة مع التغير المناخي،

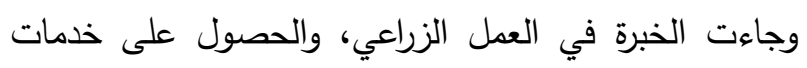

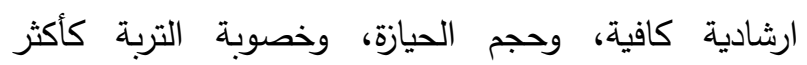
المحددات التي تفسر تطبيق الزراع لبدائل الأقلمة المختلفة.

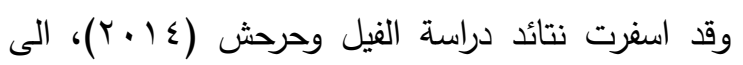

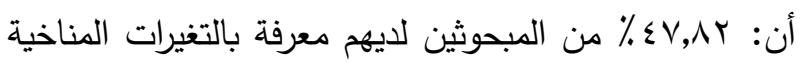

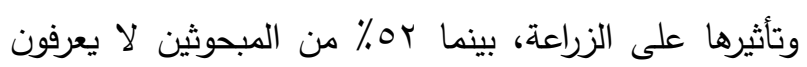
ذلك، كما ان المبحوثين الذين يعرفون التغيرات المناخية وتأثيرها على الزراعة عرفوا ذلك من خلال وسائل الاعلام سواء التليفزيون أو الصحف أو الاذاعة ، بينما المنظمات الزراعية العاملة في هذا المجال كالإرشاد الزراعي ومعاهد البحوث أو كليات الزراعة لم يكن لها أي دور يذكر في

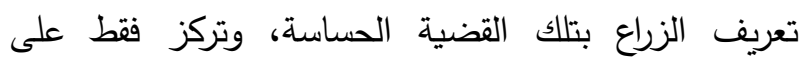

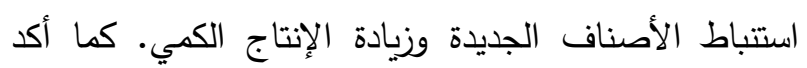
غالبية أفراد المجموعة البؤرية في القرى الثالث على أهمية متابعة جهاز الإرشاد الزراعي لتلك القضية مع الزراع، من النه خلال عمل ندوات واستتباط أصناف جديدة من المحاصيل تلوائُ مع التغيرات المناخية.
والزراعة للأمم المتحدة FAO (تغير المناخ والأمن الغذائي)

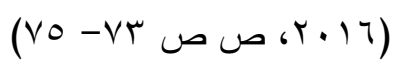

ثالثاً: مفهوم المنظمات غير الحكومية هي منظمات لها هيكل أو بنيان تتظيمي رسمي يتصف بالدوام النسبي كما أنها مسجلة ومشهرة، وهي غير حكومية "بمعنى أنها لا ترتبط ارتباطاً مباشراً بالحكومة بحيث لا تدخل ضمن البنيان الحكومي الرسمي، كما أن إدراتها ذاتية وبعيدة

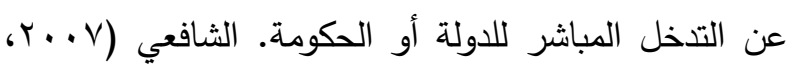
ص ص ( ) وذكر شاكر (V. . . r، ص ) انها "تلك المنظمات التي تقدم خدماتها إلى فقراء الريف بطريقة مباشرة، والتي تهتم بتحقيق التغير التدريجي من خلال تتمية الموارد البثرية لتلبية حاجاتها أو المطالبة بتحسين الخدمات الحكومية، وتركز في تقديم خدماتها على الاستشارة أو توفير المدخلات التي تمكن من تطبيق التكنولوجيا الزراعية". رابعاً: الأدوار التي تقوم بها المنظمات غير الحكومية في مواجهة التغيرات المناخية

NGOs تستطيع ان تقوم المنظمات غير الحكومية بالعديد من الأدوار أو الوظائف المختلفة فيما يخص التغيرات المناخية، على سبيل المثال، جمع بيانات المناخ الملاحظة أو المراقبة، وربط المجتمعات المحلية والمعارف التقليدية للمناخ المحلي بمنتجي المعلومات المناخية، كذلك ترجمة المعلومات المناخية التقنية إلى اللغات المحلية والأشكال غير التقنية، أيضاً توصيل معلومات الطقس والمناخ والأنذار المبكر للمستقيدين، وشرح مستويات عدم اليقين الملازمة للمعلومات المناخية، واستغلال المعلومات المناخية في صنع القرارات المحلية والوطنية. (Lindsey Jones et al, 2016, p8) ومن الأدوار الأخري لمنظمات المجتمع المدني التي ذكرها المنتدى الدولي الثامن للمنظمات غير الحكومية في معالجة تغيرات المناخ ما يلي: تثقيف وتوعية المجتمعات

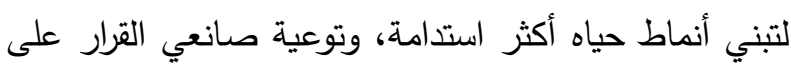


الارتباطية بين المستوى المعرفي للمبحوثين وبين المتغيرات

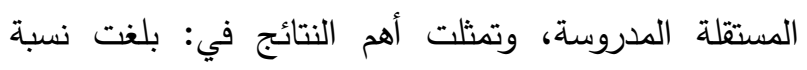
المبحوثين ذوي المستوى المعرفي الجيد بظاهرة التغير المناخي ومسبباتها سب,ץ\%٪، كذلك وجود علاقة ارتباطية معنوية بين المستوى المعرفي للزراع وكل من السن والحالة

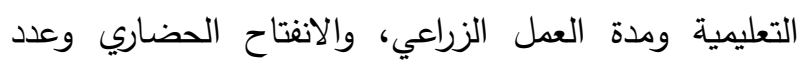
مصادر المعلومات الزراعية. وتمثلت أهم الآثار الضارة للتغيرات المناخية على الإنتاج الزراعي في: انخفاض انتاجية بعض المحاصيل الزراعية، ونقص معدلات مياه الري اللازمة للزراعة، وارتفاع معدل الاحتياج المائي لبعض المحاصيل

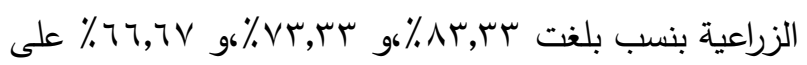
الترتيب. وكانت أهم الممارسات التي يقوم بها المبحوثين لمواجهة التأثيرات الضارة لتلك الظاهرة ما يلي: زراعة التهات حاصلات زراعية موسم نموها قصير كالخضر ، وعدم حرث الأرض الزراعية لأعماق كبيرة ، ووضع المخصبات الزراعية،

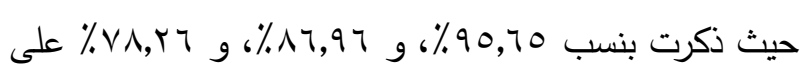
الترتيب.

دراسة Iwuchukwu.J.C,etal ( ا • ب) استهدفت الدراسة تحديد معرفة والأدوار المتصورة للمنظمات غير الحكومية في التخفيف من آثار تغير المناخ والتكيف معه في ولاية أنامبرا ، نيجيريا. وكانت أهم النتائج التي توصلت لها الدراسة أن ما لهائ يزيد عن (• (\%) من أعضاء المنظمات غير الحكومية لم

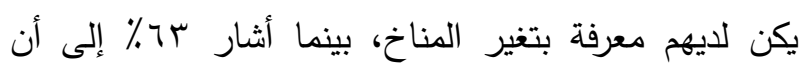

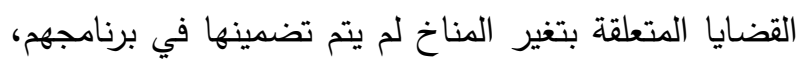

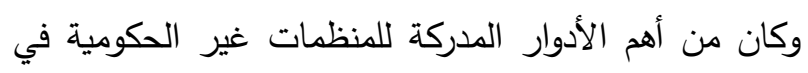
التخفيف والتكيف مع آثار التغيرات المناخية ما يلي: توعية

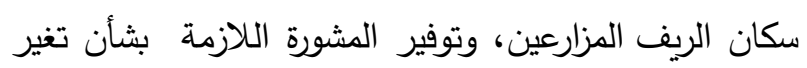

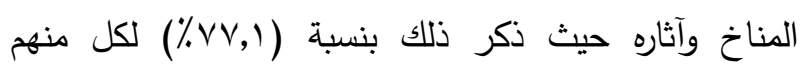
ومساعدة الحكومة في تطبيق السياسات والقوانين التي ستساعد على التخفيف من تغير المناخ ( (\%,l\%) وشددت الدراسة على الحاجة إلى القطاع الخاص وخاصة استثمار
دراسة دينا داوود (10 • ب) استهدفت الدراسة التعرف على معارف واتجاهات وممارسات الزراع بمحافظة كفر الثيخ نحو ظاهرة التغيرات المناخية، وتمثلت أهم النتائج في الآتي: وقع • ؟ ٪ من المبحوثين في فئة المعارف المتوسطة فيما يتعلق بالآثار السلبية الناتجة عن ظاهرة التغيرات

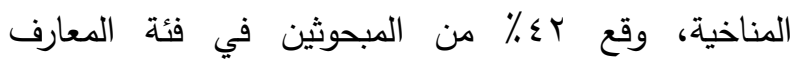
المنخفضة فيما يتعلق بكيفية التكيف مع ظاهرة التغيرات المناخية، ووقع اء٪ من المبحوثين في فئة الممارسات المرتفعة الصحيحة فيما يتعلق بظاهرة التغيرات المناخية، ووقع •• من المبحوثين في فئة الممارسات المرتفعة فيما

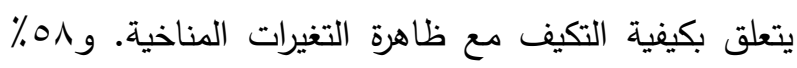
من المبحوثين وقعوا في فئة الاتجاهات المتوسطة نحو التكيف مع ظاهرة التغيرات المناخية. دراسة ايه عمر (10 • (Y) استهدفت معرفة درجة ادراك ووعي المزارعين بظاهرة التغير المناخي وتأثيراته على الزراعة وعلاقة هذا الوعي والادراك بالمتغيرات الاقتصادية والاجتماعية الخاصة بهه، وقد أظهرت النتائج ان غالبية المزارعين (r,rه\%) قد لاحظوا تغيرات في الأنماط المناخية خاصة في درجة الحرارة والأمطار، وبرغم ادراك غالبية المزارعين للظاهرة إلا ان إدراكهم للاثار السلبية لها ليست عالية حيث أظهرت النتائج أن 0,0 1 ف فرط من المبحوثين لديهح ادراك مرتفع بالاثار السلبية لتغير المناخ، واظهرت النتائج أن نسبة محدودة من العينة (ه,0\%) لديهم وعي دري بالظاهرة وآثارها المحتملة على الزراعة، وان مستوى تعليم المزارعين مرتبط معنويا بدرجة ادراكهم للظاهرة. كما ان نسبة

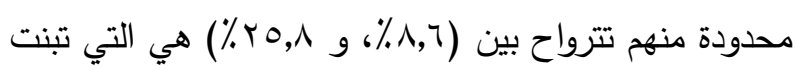
اجراءات للتكيف مع اثاره. دراسة نجوى خطاب (T ( • ( )، استهدفت التعرف على: المستوى المعرفي للمبحوثين بظاهرة التغير المناخي

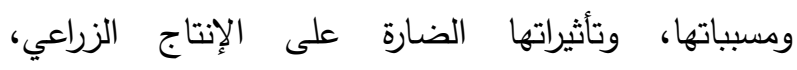

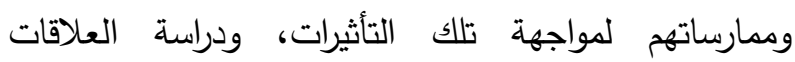


- - تم اختيار مركزي الفيوم وطاميه لإجراء الدراسة عليهما

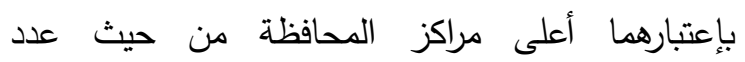

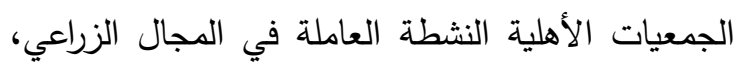

كما هو موضح بجدول (1).

جدول ا.توزيع الجمعيات الأهلية العاملة في المجال موضئ

\begin{tabular}{|c|c|}
\hline \multicolumn{2}{|c|}{ الزراعي على مستوى مراكز محافظة الفيوم } \\
\hline عدد الجمعيات & المركز \\
\hline 9 & الفيوم \\
\hline$\wedge$ & طامية \\
\hline ○ & ابشواي \\
\hline r & أطساً \\
\hline r & يوسف الصديق \\
\hline r & | سنورس \\
\hline$r$. & الاجمالى \\
\hline
\end{tabular}

المصدر: مديرية التضامن الاجتماعي بالفيوم (الاتحاد النوعي للتتمية والبيئة

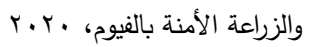

- - وتم اختيار قريتين من كل مركز وهما قريتي دمشقين

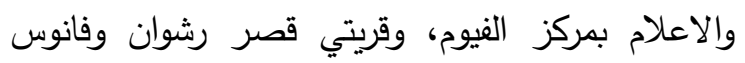
بمركز طاميه، وتم اخذ عينة عشوائية بسيطة من اجمالي المستفيدين من خدمات تلك الجمعيات والبالغ

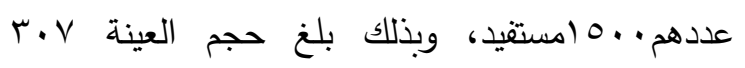

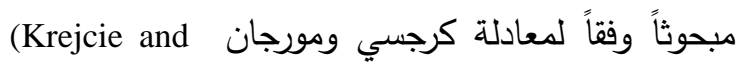
، كما هو موضح بجدول (1) Morgan, 1970. P,608) وقد جمعت البيانات الميدانية باستخدام استمارة استبيان

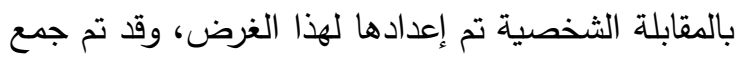
بيانات هذه الدراسة خلال شهري سبتمبر واكتوبر لعام .r. r.

\section{ج- المتغيرات البحثية وطرق قياسها:}

العن: تم التعبير عن هذا المتغير بسؤال المبحوثين عن أعمارهم لأقرب سنة في وقت تجميع بيانات الدراسة. المستوى التعليمي: يقصد به حالة المبحوث من حيث كونه

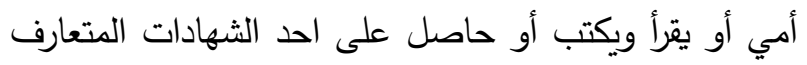

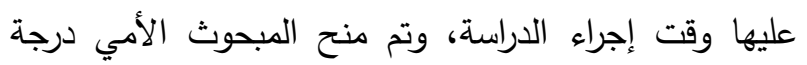
واحدة، ولمن يقرأ ويكتب درجتان، والحاصل على شهادة التهاء ابتدائية (ך درجات)، وشهادة اعدادية (9 درجات)، وشهادة
الهنظمات غير الحكومية ومشاركتها في القضايا العالمية والحساسة مثل تغير المناخ. تعقيب على الاراسات السابقة: يتضح من استعراض ملاض الدراسات والبحوث السابقة ما يلي: تناولت معظم الدراسات السابقة تحديد مستوى معرفة وإدراك الزراع بظاهرة التغيرات المناخية وآثارها السلبية، وكذلك ممارساتهم للتأقلم مع تلكانك الظاهرة، واتضح أن مستوى معرفة وإدراك الزراع المبحوثين كانت اما منخفضة أو متوسطة بتلك الظاهرة، وأثارها السلبية على القطاع الزراعي، وهو ما يشير إلى ضرورة زيادة وعي متئي

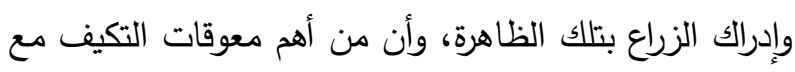
آثار تلك الظاهرة هو ارتفاع تكاليف ممارسات التكيف وقصور التمويل لدي غالبية المبحوثين، كما اتضح غياب دور المنظمات الزراعية العاملة في هذا المجال وعلى رأسها لإية التهاب

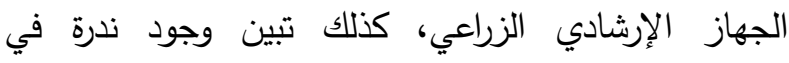
الدراسات التي تناولت دور المنظمات غير الحكومية في هذا كأل الهجال، وهو ما ستهتم به الدراسة الحالية، وقد استفادت

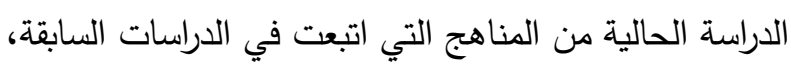
وكذا المتغيرات البحثية التي شملتها تلك الدراسات. ثالثاً: الأسلوب البحثي: ويتضمن منطقة وعينة الدراسة، والمتغيرات البحثية، بالإضافة إلى أسلوب قياسها، والأساليب الاحصائية المستخدمة، وذلك على النحو التالي: أ- منطقة الدراسة: تحددت منطقة الدراسة لهذا البحث في محافظة الفيوم، والتي تعتبر إحدى محافظات إقليم شمال

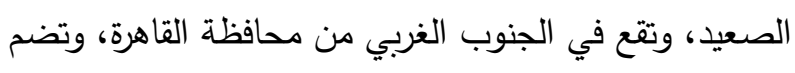
محافظة الفيوم ستة مراكز إدارية هي: الفيوم، وسنورس، وابشواي، واطسا، وطاميه، ويوسف الصديق.

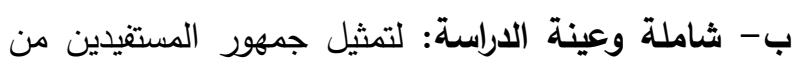

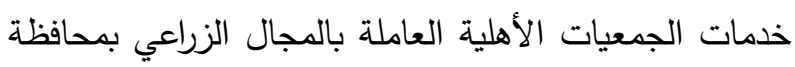
الفيوم، فقد اختيرت عينة بحثية من المستفيدين من تلك الكيات الخدمات، وقد تمثلت إجراءات سحب هذه العينة فيما يلي: 
الدرجات السابقة لتعبر عن درجة انفتاحه على العالم الخارجي.

الوعي بظاهرة التغير المناخي: يقصد به مدى معرفة المبحوث بمفهوم التغير المناخي وأسبابه، وقد أعطيت الدرجة

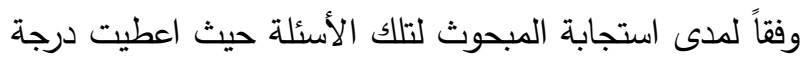
واحدة في حالة المعرفة، وصفر في حالة عدم المعرفة، اما عن تعدد اسباب أو مصادر التغير المناخي فقد تم اعطاء درجة لكل سبب يعرفه المبحوث، ثم حسبت درجة وعي المبحوث من خلال حساب مجموع الدرجات التي حصل عليها. التعرض لمصادر المعلومات الزراعية: يقصد به درجة اتصال المبحوث بمصادر المعلومات الرسمية والتقليدية والجماهيرية التي يستقي منها معلوماته عن التغيرات المناخية، وقد تم قياس هذه المتغير من خلال المؤشرات

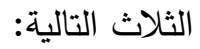

- - الأهمية النسبية لمصادر المعلومات: وتم قياسه من

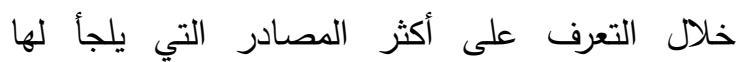
المبحوث للحصول على المعلومات. - مدى التعرض لمصادر المعلومات: تم تخصيص ثلاث درجات للتعرض الدائم ودرجتان للتعرض أحياناً ودرجة واحدة للتعرض النادر وصفر في حالة عدم التعرض. - درجة الاستفادة من مصادر المعلومات: تمثل درجة تقدير

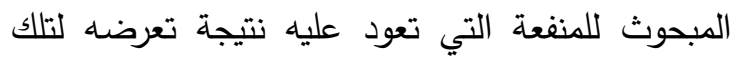
المصادر، وتم تخصيص ثلاث درجات للاستفادة المرتفعة، ودرجتان للاستفادة المتوسطة، ودرجة للاستفادة المنخفضة، وصفر لانعدام الاستفادة.

الطرق الإرشادية المستخدمة من المنظمات غير الحكومية لنقل المعلومات والممارسات للمبحوثين: تم سؤال المبحوثين عن تلك الطرق التي تستخدمها تلك المنظمات في توصيل وتتفيذ المعلومات والممارسات الخاصة بالتغلب على ظاهرة
ثانوية أو ما يعادلها (Y ( درجة)، والبكالوريوس أو ما يعادلها (7 (1 آدرجة). حجم الحيازة الزراعية: يقصد به مساحة الأرض الزراعية التي يحوزها المبحوث وقت جمع البيانات، وقد تم قياسه باستخدام الأرقام الخام للأفدنة.

حجم الحيازة الحيوانية: يقصد به عدد الحيوانات المزرعية التي يمتلكها المبحوث، وقد تم قياسه باستخدام الأرقام الخام للحيوانات التي يحوزها المبحوث. التفرغ للعمل الزراعي: تم قياسه باعطاء ثلاث درجات للمتفرغ تماماً، ودرجتان للمتفرغ إلى حداًما، ودرجة واحدة لاء

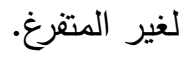

مستوى الطموح: يقصد به تطلعات المبحوث ورغبته في تحقيق مستوى معيشي أفضل، وقد تم قياسه من خلال مستوى الطموح التعليمي، وتم التعبير عنه من خلال مدى

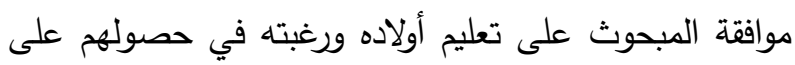
شهادات، وقد خصصت درجة واحدة للموافقة وصفر في حالة

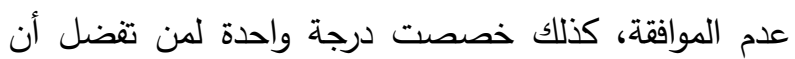
تعلمه أكثر من الذكور والاناث، ودرجتان في حالة الرد باستجابة الاثثين معا، كذلك خصصت درجة واحدة لرغبته في حصول أولاده على الشهادة الابتدائية، ودرجتان للشهادة الاعدادية، وهكذا، اما مستوى الطموح الاستثماري فقد تم قياسه من خلال المجالات التي يرغب استثمار أمواله فيها، وتم اعطاء درجة واحدة لكل رغبة. ثم حسبت درجة مستوى الطموح من خلال مجموع الدرجات التي حصل عليها المبحوث في المؤشرين.

الانفتاح على العالم الخارجي: تم قياسه من خلال سؤال المبحوث مجموعة من العبارات تعكس مستوى انفتاحه الثقافي ومدى اتصاله بالعالم الخارجي، واعطيت ثلاث درجات للتعرض الدائم، ودرجتان للتعرض أحياناً، ودرجة للتعرض النادر، وصفر في حالة عدم التعرض، ثم جمعت التغير المناخي للمبحوثين. 
جدول r . حجم الثاملة والعينة من الزراع المستفيدين من خدمات الجمعيات الأهلية العاملة في المجال الزراعي بالقرى

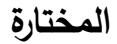

\begin{tabular}{|c|c|c|c|}
\hline حجم العينة & حجم الثاملة & المركز & القربة \\
\hline $11 \varepsilon$ & 07. & الفيوم & دمشقين \\
\hline$v \cdot$ & $r \varepsilon$. & الفيوم & الاعلام \\
\hline VY & ro. & طاميه & قصر رشوان \\
\hline 01 & ro. & طاميه & فانوس \\
\hline$r \cdot v$ & $10 \ldots$ & & الاجمالى \\
\hline
\end{tabular}

للاستفادة المتوسطة ودرجة للاستفادة المنخفضة، وصفر لإنعدام الاستفادة، ثم جمعت الدرجات التي حصل عليها المبحوث لتمثل درجة استفادته.

أهمية الخدمات الإرشادية المقدمة من وجهة نظر المبحوثين: تمثل درجة تقدير المبحوث لأهمية الخدمات أو المعلومات التي يتلقاها في هذا المجال وتأثيرها على التغير المناخي، وقد اعطيت r درجات للأهمية المرتفعة ودرجتان للأهمية المتوسطة ودرجة للأهمية المنخفضة، وصفر لإنعدام

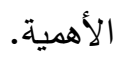

د- أساليب التحليل الاحصائي: لتحليل بيانات الدراسة تم استخدام النسب المئوية والتكرارات، والمدى، والمتوسط الحسابي، والانحراف المعياري، ومعامل الارتباط البسيط لبيرسون، وتحليل الانحدار المتدرج Regression Analysis .Step Wise Multiple

\section{النتائج ومناقشتها}

1 - الخصائص والصفات المميزة للمبحوثين:

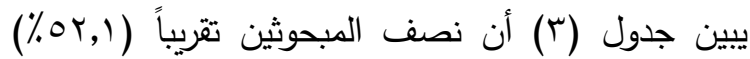
يقعون في الفئة العمرية المتوسطة، وكان عـ\% تقريباً من المبحوثين حاصلين على مؤهل سواء كان متوسط أو جامعي

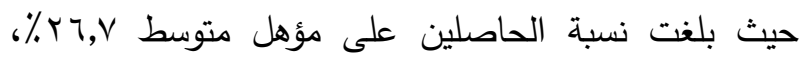

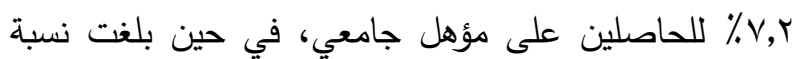

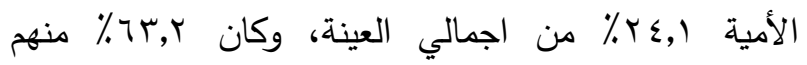

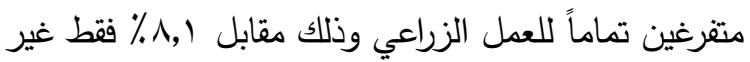

مدى استمرارية تقديم الخدمات الإرشادية الزراعية للمبحوثين من الجمعيات الأهلية: تم تخصيص الدرجات (T، Y، ( ) للاستجابات مستمرة، وإلى حدا ما، وغير مستمرة على الترتيب. مدى كفاية الخدمات المقدمة: وتم قياسه من خلال اعطاء الدرجات (T، Y Y، ( ) لمدى كفاية الخدمات المقدمة سواء كانت كافية أو إلى حدا ما أو غير كافية على الترتيب. الخدمات الإرشادية المقدمة من الجمعيات الأهلية فيما يتعلق بالتغيرات المناخية: هي مجموعة من الأنشطة والخدمات الإرشادية الزراعية المتعلقة بظاهرة التغيرات المناخية، والتي قد تم الاطلاع عليها في الادبيات والدراسات التي تمت في ذلك المجال، وقد تم قياسها من خلال سؤال المبحوثين عن مدى قيام الجمعيات الأهلية محل الدراسة بتقديم تلك الخدمات من عدمه، وقد اعطيت الدرجات (T، Y، (، صفر ) للاستجابات تقدم بصفة دائما، تقدم احياناً، نادراً، ولا تقدم على الترتيب، وقد تم حساب الدرجات التي حصل عليها المبحوث، وتراوح المدى الفعلي بين (9 1- . . 7) ووفقاً لذلك تم تقسيم مستوى تقديم الخدمات الإرشادية الزراعية إلى ثلاث مستويات هي: مستوى تلقي منخفض أقل من سب

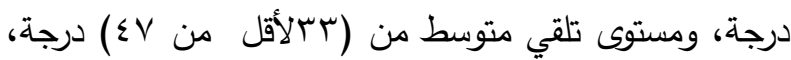
ومستوى تلقي مرتفع V Vدرجة فأكثر • الاستفادة من الخدمات الارشادية الزراعية المقدمة: تمثل درجة تقدير المبحوث للمنفعة التي تعود عليه نتيجة تلقيه تلك الخدمات، وقد اعطيت ب درجات للاستفادة المرتفعة ودرجتان 
جدول ب. توزيع المبحوثين وفقاً للخصائص المميزة لهم

\begin{tabular}{|c|c|c|}
\hline \multicolumn{3}{|c|}{ الخصائص } \\
\hline$\%$ & العدد & السن \\
\hline IT,V & $r q$ & اقل من Vr سنـه \\
\hline or, 1 & 17. & من VT إلى أقل من Y O سنه \\
\hline ro,r & $1 \cdot 1$ & or سنة فأكثر \\
\hline $1 \ldots$ & $r \cdot v$ & الاجمالى ل \\
\hline$\%$ & العدد العد & الحالة التعليمية \\
\hline$r \xi, 1$ & $V \varepsilon$ & \\
\hline 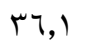 & 111 & بدون شهادة \\
\hline $0, r$ & 17 & لمى ابتدائية \\
\hline$\cdot, \mathrm{V}$ & r & ي إعدادية \\
\hline r૫, & Ar & لى مؤهل "متوسط \\
\hline$V, r$ & rt & لى مؤهل جامعى \\
\hline $1 \ldots$ & $r \cdot v$ & الاجمالّ \\
\hline$\%$ & 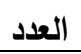 & التفرغ للعمل الزراعى \\
\hline $4 \pi, 4$ & $19 \varepsilon$ & متفرغ \\
\hline$r \wedge, \vee$ & $\wedge \wedge$ & إلى حدا ما \\
\hline$\Lambda, 1$ & ro & غير متقرغ \\
\hline $1 \ldots$ & $r \cdot v$ & الآمالى \\
\hline$\%$ & العدد & حجم الحيازة الزراعية \\
\hline $70, r$ & r.. & أقل من ع أفدنة \\
\hline$r \wedge, \vee$ & $\wedge \wedge$ & فدنة لأقل من V أفدنه \\
\hline 7,1 & 19 & v أفندة فأكثر \\
\hline $1 \ldots$ & $r \cdot v$ & الاجمالى \\
\hline$\%$ & 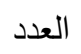 & حجم الحيازة الحيوانية \\
\hline$r \leq, 1$ & $V \varepsilon$ & لا يحوز ل ل \\
\hline r,o & 114 & أقل من V وحدات حيوانية \\
\hline$r \cdot, \tau$ & $9 \leq$ & من V لأقل من Y I وحدة حيوانية \\
\hline$\wedge, \wedge$ & rV & rا وحدة حيوانية فأكثر " \\
\hline $1 \ldots$ & $r \cdot v$ & \\
\hline$\%$ & 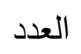 & الطموح \\
\hline$\leqslant 0,9$ & $1 \leqslant 1$ & منخفض( اقل من • درجات) \\
\hline $0 ., r$ & $10 \varepsilon$ & متوسط (من · ا لأقل من r ا) \\
\hline$r, q$ & ir & مرتفع (r ا درجة فأكثر) \\
\hline $1 \ldots$ & $r \cdot v$ & الاجمالى \\
\hline$\%$ & 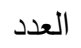 & الانفتاح على العالم الخارجى \\
\hline ґ, & 119 & منخفض( اقل من · ( درجات) \\
\hline rq, ₹ & $|r|$ & متوسط (من · الأقل من ع أ درجة) \\
\hline$\langle, \Lambda$ & TV & مرتقع (ع ا درجة فأكثر) \\
\hline $1 \ldots$ & $r \cdot v$ & الاجمالى \\
\hline
\end{tabular}

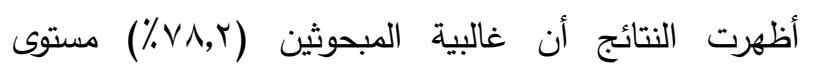
انفتاحهم على العالم الخارجي أما متوسط أو منخفض حيث

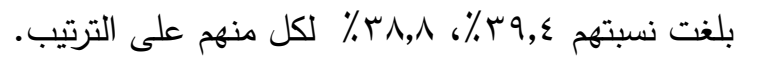

متفرغين له، وكان غالبيتهم (ro, 7\%) ذوي حيازات مزرعية

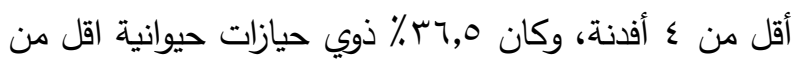
V وحدات، وأن Y, ب. ٪ ذ ذوي مستوى طموح متوسط، كمان 
انخفاض مستوى الوعي لديهم، كما أوضح جدول (ج) أن

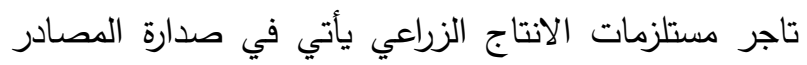

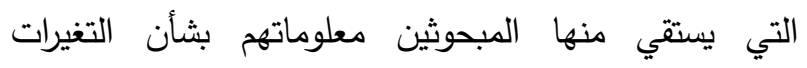

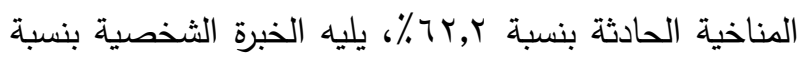

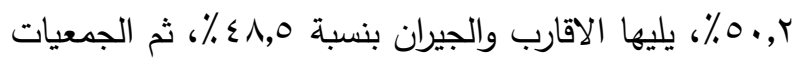

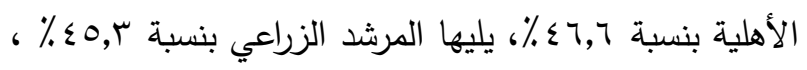

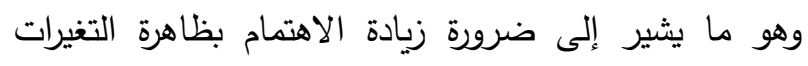

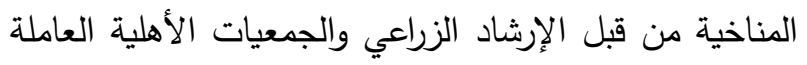

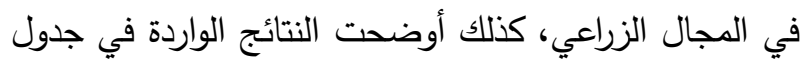

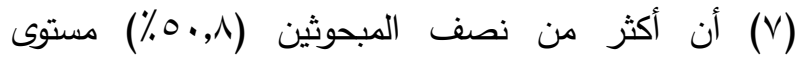

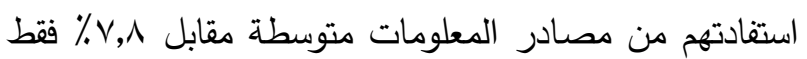

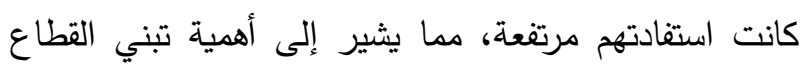

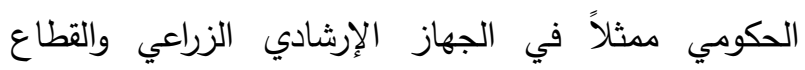

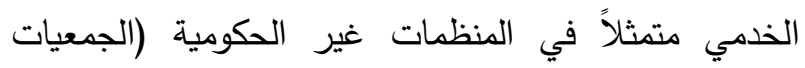

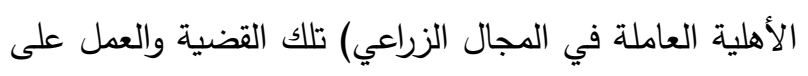
رفع وعي الزراع بها وبمسبباتها وكيفية التكيف معها. جدول ه. توزيع المبحوثين وفقاً لتعرضهم لمصادر

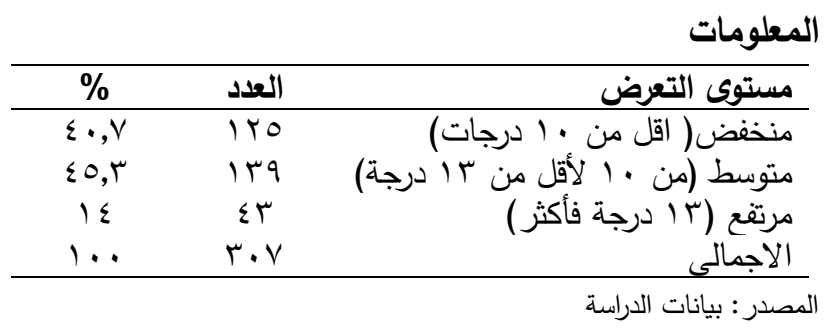

r - الوعي بظاهرة التغير المناخي

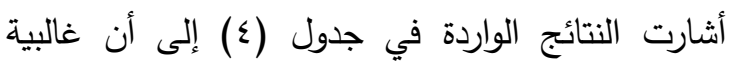

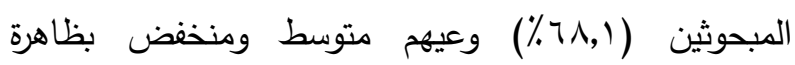

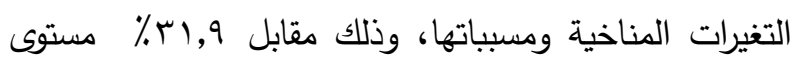
وعيهم مرتفع بتلك الظاهرة ومسبباتها. وهو ما يشير إلى هيلى ضرورة العمل على زيادة وعي المزارعين بتلك الظاهرة وتأثيراتها المختلفة على الزراعة من خلال زيادة مصادر المعلومات والقنوات الاتصالية والمنظمات الزراعية المهتمة

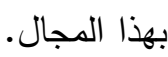

جدول ؛. توزيع المبحوثين وفقاً لوعيهم بظاهرة التغير

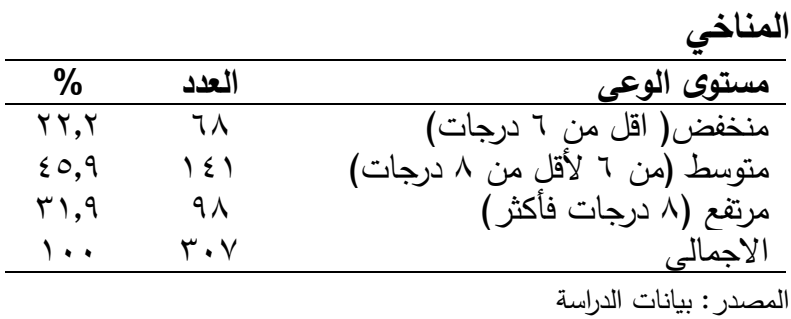

ץ- التعرض لمصادر المعلومات، وأهيتها النسبية،

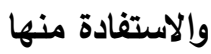

أوضحت النتائج الواردة بجدول (0) أن r,ه؛ ٪ من

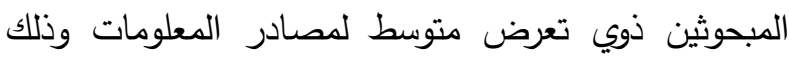

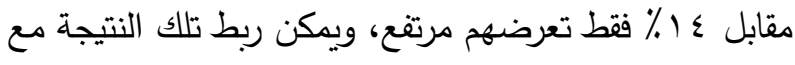
مستوى وعيهم المتوسط بتلك الظاهرة، فانخفاض مستوى التعرض لمصادر المعلومات قد يسهم بشكل كبير في 
جدول 7.

\begin{tabular}{|c|c|c|c|}
\hline الأهمية النسبية & $\%$ & التكرار (ن = r.v & مصدر المعلومات \\
\hline$r$ & $0 ., Y$ & $10 \leqslant$ & الخبرة الشخصية \\
\hline r & $\varepsilon \wedge, 0$ & $1 \leqslant 9$ & الاقارب والجيران \\
\hline- & - & - & الأبناء \\
\hline 0 & $\varepsilon 0, r$ & $1 \% q$ & المرشد الزراعى \\
\hline 1 & Tr, & 191 & تاجر مستلزمات الانتاج \\
\hline 7 & $\varepsilon r$ & 149 & 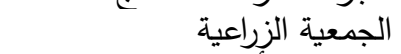 \\
\hline$\varepsilon$ & $\leq 7,7$ & $1 \leq r$ & الجمعية الأهلية \\
\hline- & - & - & محطات البحوث الزراعية \\
\hline- & - & - & الراديو \\
\hline$\checkmark$ & r & 114 & البرامج التليفزبونيه \\
\hline- & - & - & قناة مصر الزراعية \\
\hline$\wedge$ & r, & $9 \wedge$ & الانترنت \\
\hline- & - & - & المجلات الزراعية \\
\hline- & - & - & النشرات الفنية " \\
\hline & & - & الجرائد ال \\
\hline
\end{tabular}

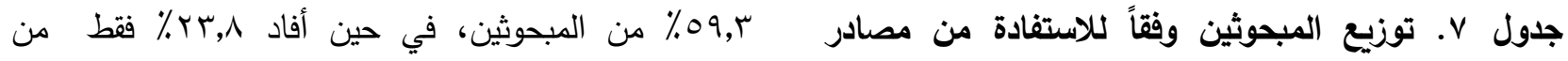

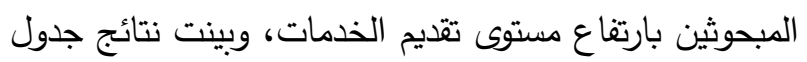

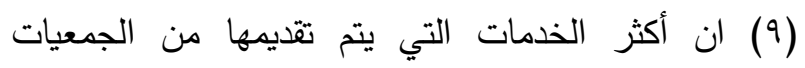
للمبحوثين والخاصة بالتوعية بأسباب حدوث الظاهرة وآثارها

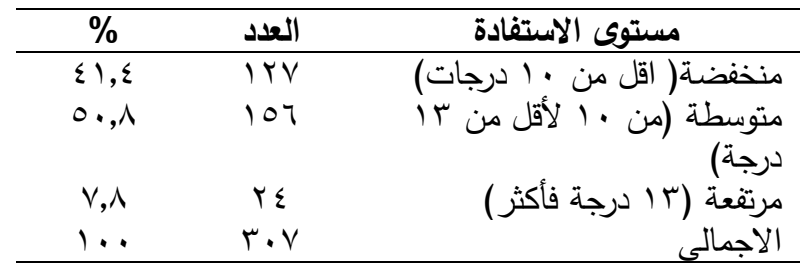

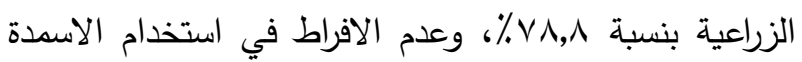

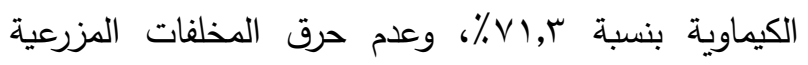

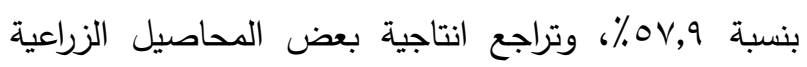
نتيجة تغير درجات الحرارة بنسبة ، حيث ذكر ذلك بنسبة

ع - الخدمات الإرشادية الزراعية المقدمة من الجمعيات الأهلية في مجال التغيرات المناخية:

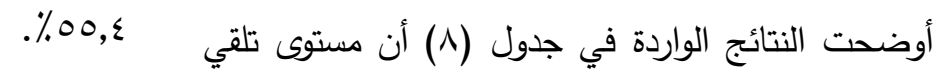

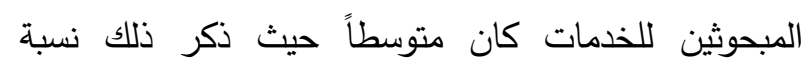

جدول ^. توزيع المبحوثين وفقاً لمستوى تقديم الخدمات الإرشادية المقدمة من الجمعيات الأهلية

\begin{tabular}{|c|c|c|}
\hline$\%$ & العدد & الخدمة المقدمة \\
\hline 17,9 & or & منخفض( اقل من سٓ درجة) \\
\hline $09, r$ & IAr & متوسط (من سT لأقل من VI درجة) \\
\hline$r \mathrm{r}, \Lambda$ & $\mathrm{Vr}$ & مرتفع (V乏 درجة فأكثر) \\
\hline $1 \ldots$ & $r \cdot v$ & الاجمالى \\
\hline
\end{tabular}


جدول 9.

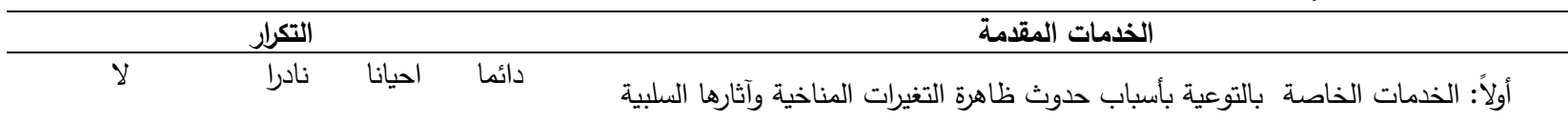

\begin{tabular}{|c|c|c|c|c|}
\hline rA. & IV & $1 \cdot$ & - & 1- التوعية بعدم قطع الأشجار الخضراء \\
\hline$r \cdot v$ & - & - & - & r- التوعية بعدم الاقراط فى استخدام الوقود (الفحم- البترول) \\
\hline$r \cdot v$ & - & - & - & r- التوعية بنظافة اماكن تربية الماشية لتجنب الغازات المنبعثة من تربية الماشية \\
\hline- & - & 70 & $r \leqslant r$ & 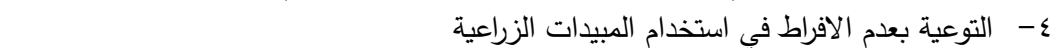 \\
\hline- & - & $\wedge \wedge$ & r19 & 0- التوعية بعدم الافراط فى استخدام الاسمدة الكيماوية \\
\hline- & r & irv & ive & 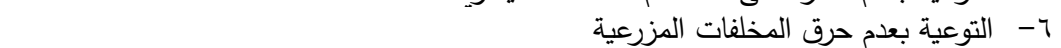 \\
\hline YTY & $\mu_{1}$ & ro & 10 & - - التوعية بعدم حرق المخلفات المنزلية \\
\hline$r \cdot v$ & - & - & - & 1- - التوعية بضرورة تقليل معدل الفاقد والمهدر من الأغذية \\
\hline IVT & $\uparrow$ & 07 & 11 & 9- تعريف الزراع بالآثار السلبية المحتملة على مياه الري المتوفرة. \\
\hline iv & iv & $1 . r$ & iv. & 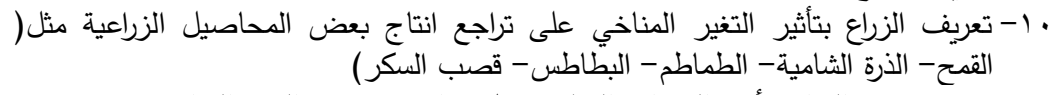 \\
\hline 111 & $1 \cdots$ & 04 & $\varepsilon \cdot$ & 11- تعريف الزراع بتأثير التغيرات المناخية على تراجع خصوبة التربة الزراعية \\
\hline 110 & VT & $\varepsilon r$ & $\vee$ & النبات نتيجة ارتفاع درجات الزراع بأثر التغيرات المناخية على انتشار الآفات والأمراض التي تصيب \\
\hline IVT & $v r$ & $\varepsilon r$ & 19 & rا- توعية الزراع بتأثر التغيرات المناخية على زيادة الاستهلاك المائي للمحاصيل \\
\hline$r \cdot v$ & - & - & - & الحرارة. تعريف الزراع بظهور بعض الأمراض التي تصيب الماشية نتيجة التغيرات في درجة \\
\hline$r \cdot v$ & - & - & - & المناخية $\quad$ توعية الزراع بتراجع القدرة الانتاجية للماشية من الالبان واللحوم نتيجة التغيرات \\
\hline ץฯ & rq & 1. & - & تعريف الزراع بتأثير التغيرات المناخية على تغيير اماكن زراعة بعض المحاصيل \\
\hline- & - & TrT & ivo & 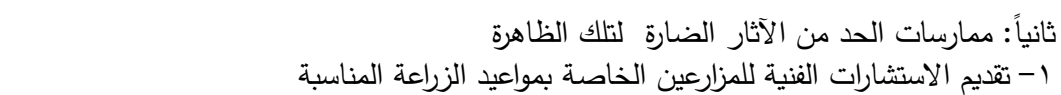 \\
\hline$r \leq \tau$ & 纟o & 17 & - & r- تعريف المزارعين بالآصناف المقاومة للجفاف والتملوحة وتوفيرها. \\
\hline 1. & 09 & 174 & $v ч$ & r- تعريف المزارعين بالعدد المناسب للنباتات حسب كمية المياه المتوفرة \\
\hline- & 1 & 7. & $r \leq T$ & ع - تثجيع الزراع على الزراعات العضوية، ومساعدتهم للتحول للزراعة العضوية. \\
\hline- & r & $1 \cdot \varepsilon$ & $r \cdot 1$ & ه- تدريب الزراع على تدوير المخلفات الزراعية والعضوية. \\
\hline 1 & r & $\uparrow 1$ & rrt & 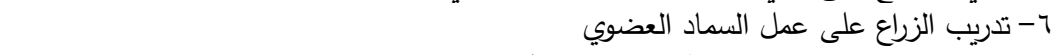 \\
\hline rol & rq & $1 \varepsilon$ & 1 & V- توفير الاشجار وحث الزراع على زيادة المسطحات الخضراء والتثجير \\
\hline ir & - & vч & r19 & ^- اقامة ندوات لحث الزراع على عدم تلوث مياة الترع والمصارف والمساهمة في تطهيرها \\
\hline IVT & 94 & « & r & 9- نشر طرق الري الحديثة لترشيد استخدام المياه وتجنب الري الزائد \\
\hline$r \cdot v$ & - & - & - & 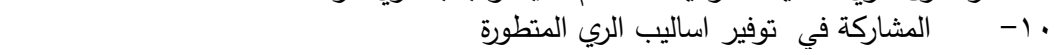 \\
\hline 1 & $0 \leqslant$ & $17 \varepsilon$ & $\wedge \wedge$ & تقديم التوصيّات الفنية للحفاظ على خصوبة التربة. \\
\hline זיז & 纟o & - & - & نشر التشريعات الخاصة بحماية البيئة من التلوث \\
\hline 1 & 1 & $1 \mathrm{ir}$ & 171 & عمل ندواتً عن كيفية الحفاظ على البيئة من التلوث \\
\hline r^o & rt & - & - & ـ ا- عقد ندوات لترشيد استخدام الطاقة (التقليل من استهلاك الكهرباء والفحم والبترول) \\
\hline$r \cdot v$ & - & - & - & التغيرات المناخية - عدوات للتعريف بالأمراض التي تصيب الانسان والحيوان الناتجة عن ظاهرة \\
\hline rar & iv & - & - & هن انتشارها عقد ندوات للتعريف بالتغيير في انواع وانماط الحشرات ناقلات الامراض وكيفية الحد \\
\hline 11 & 1 & $\wedge \uparrow$ & $r \cdot 9$ & 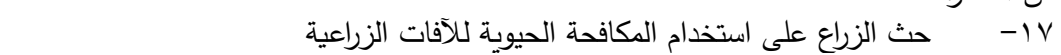 \\
\hline rᄉ & 74 & 149 & $7 \varepsilon$ & الانذار المبكر بالأوبئة \\
\hline
\end{tabular}




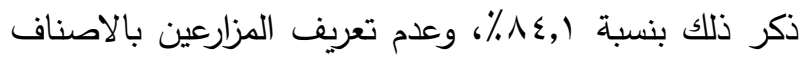

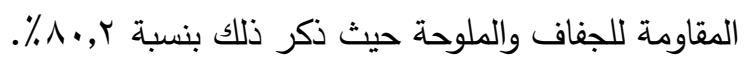
ه- مستوى استفادة المبحوثين من الخدمات الإرشادية الزراعية المقدمة لهم:

يبين جدول (·) (1) أن مستوى استفادة المبحوثين من الخدمات والأنشطة المقدمة لهم كانت اما منخفضة حيث ذكر

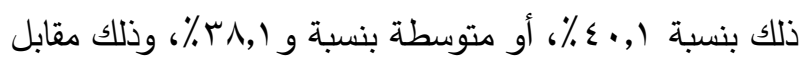

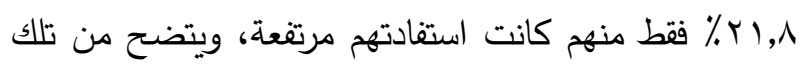
النتائج أن حوالي أربعة اخماس المبحوثين استفادتهم من الخدمات الإرشادية كانت منخفضة ومتوسطة، وقد يرجع ذلك الك إلى أن بعض الخدمات تعتمد على مدى معرفة المبحوثين بالأسباب التي تؤدي الي تفاقم تلك الظاهرة، وعدم توفير البديل المناسب لهم، أو لعدم قدرة المبحوثين على تنفيذ تلك

التوصيات بشكل دائم للحد من الآثار السلبية لتلك الظاهرة.

جدول . . توزبع المبحوثين لمستوى الاستفادة من الخدمات الإرشادية المقدمة من الجمعيات الأهلية

\begin{tabular}{|c|c|c|}
\hline$\%$ & العدد & مستوى الاستفادة \\
\hline$\varepsilon \cdot, 1$ & ITK & درجة) \\
\hline
\end{tabular}

\begin{tabular}{|c|c|c|}
\hline$r \wedge, 1$ & $11 \mathrm{~V}$ & متوسطة (من V N لأقل من \\
\hline r,$\wedge$ & TV & مرتفعة (.0 درجة فأكثر) \\
\hline $1 \ldots$ & $r \cdot v$ & الاجمالى \\
\hline
\end{tabular}

7- مدى استمرارية الخدمات الإشادية المقدمة من الجمعيات الأهلية: - الجمات

يبين جدول (1) أن أقل من ثلث المبحوثين(9,1)

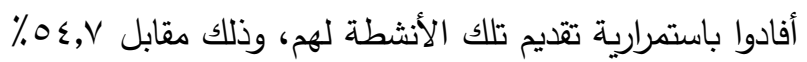

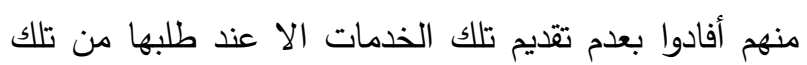
الجمعيات، وهو ما قد يفسر الاستفادة المنخفضة والمتوسطة من تلك الخدمات، في انها لا تقدم لهم بصفة مستمرة
أما فيما يتعلق بالخدمات الإرشادية الزراعية المقدمة من تلك الجمعيات والخاصة بالحد من اثار تلك الظاهرة، فكانت كالتالي: تشجيع الزراع على التحول للزراعات العضوية بنسبة

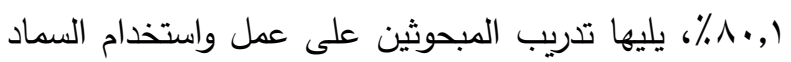

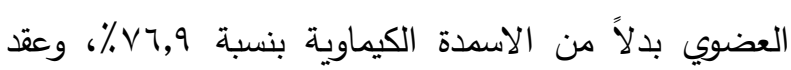

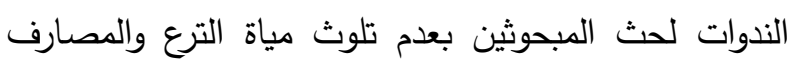
ومساعدتهم على تطهيرها بنسبة r. 1\%٪، واستخدام المكافحة

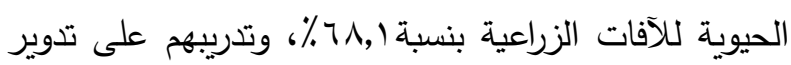
المخلفات الزراعية بنسبة 10,0٪\%

بينما اجمع المبحوثين على عدم تلقيهم الخدمات التالية:

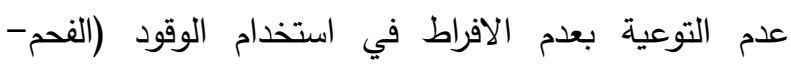
البترول)، وعدم التوعية بنظافة اماكن تربية الماشية لتجنب

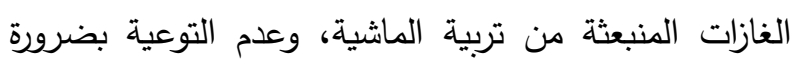
تقليل معدل الفاقد والمهدر من الأغذية، وعدم تعريف الزراع بظهور بعض الأمراض التي تصيب الماشية نتيجة التغيرات في درجة الحرارة، وعدم توعية الزراع بتراجع القدرة الانتاجية للماشية من الالبان واللحوم نتيجة التغيرات المناخية. وفيما يتعلق بتعريف المبحوثين بممارسات التغلب على تلك الظاهرة فأن أكثر الخدمات التي لا تقدم لهم تمثلت في: عدم المشاركة في توفير اساليب الري المتطورة، وعقد ندوات للتعريف بالأمراض التي تصيب الانسان والحيوان الناتجة عن ظاهرة التغيرات المناخية، حيث اجمع المبحوثين على عدم تلقيهم تلك الخدمات، يليها عدم عقد ندوات للتعريف بالتغيير في انواع وانماط الحشرات ناقلات الامراض وكيفية الحد من انتشارها حيذ ذكر ذلك بنسبة ؟0,\%٪، وعدم اقامة ندوات لتوعية المبحوثين بأهمية ترشيد الطاقة حيث ذكر ذلك بنسبة

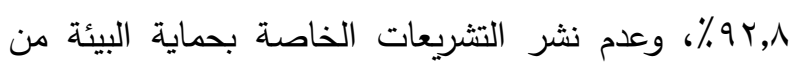
التلوث حيث ذكر ذلك بنسبة r,^,٪، وعدم توفير الاشجار وحث الزراع على زيادة المسطحات الخضراء والتشجير حيث 
جدول با ا. الطرق الإرشادية المستخدمة في تنفيذ وتقديم الخدمات للمبحوثين

\begin{tabular}{|c|c|c|}
\hline$\%$ & 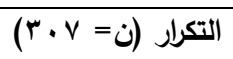 & الطريقة الإرشادية \\
\hline $1 \ldots$ & $r \cdot v$ & عقد الاجتماعات الإرشادية \\
\hline$\wedge r, \varepsilon$ & ror & الايضاح العملى \\
\hline$\bullet \wedge, q$ & 101 & زيارة المزارع فى حقله \\
\hline rA,, & $\wedge$ & توزيع مطبوعات إرشادية \\
\hline
\end{tabular}

9- تأثير بعض الخصائص المدروسة على درجة الاستفادة

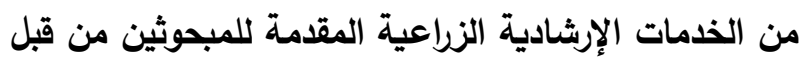

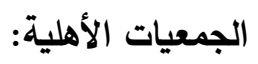

أوضحت بيانات الجدول (ع () وجود علاقة معنوية بين درجة الاستفادة من الخدمات الإرشادية الزراعية المقدمة من

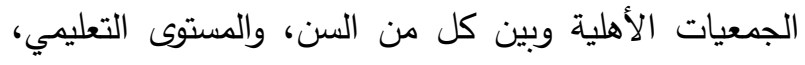

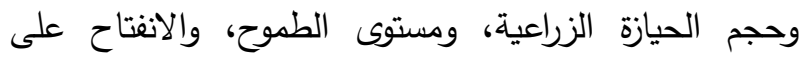
العالم الخارجي، والوعي بظاهرة التغير المناخي، والتعرض لكصادر المعلومات، والاستفادة من مصادر المعلومات، التاني،

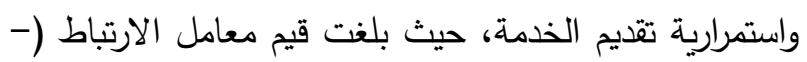

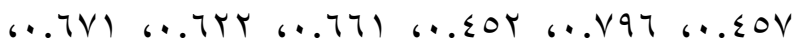

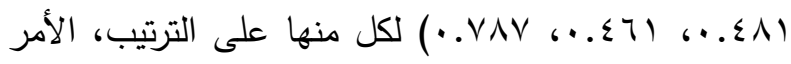

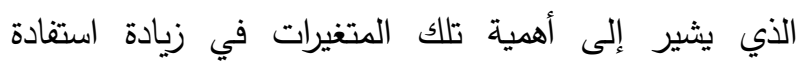

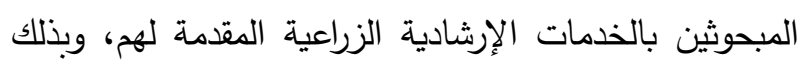
أمكن رفض الفرض الاحصائي فيما يتعلق بتلك المتغيرات،

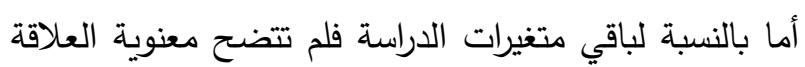
بينها وبين مستوى الاستفادة من الخدمات المقدمة، وبناءاً

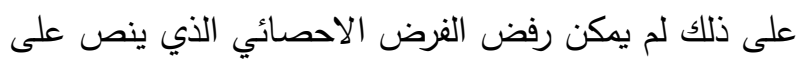

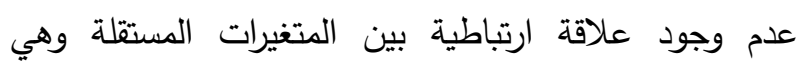
الحيازة الحيوانية، والتترغ للعمل الزراعي، وكفاية الخدمات

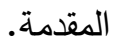

جدول 11. توزيع المبحوثين للدى استمرارية تقديم الخدمات ارشادية في هذا المجال

\begin{tabular}{|c|c|c|}
\hline$\%$ & العداد ال الع & الإرشادرية الخدمات \\
\hline$r 1,9$ & 91 & مستمرة \\
\hline $0 \leqslant, V$ & 171 & عند الطلب \\
\hline IT,r & «1 & غير مستمرة \\
\hline$\ldots$ & $r \cdot V$ & الاجمالى \\
\hline
\end{tabular}

-V مدى كفاية الخدمات والأنثطة المقدمة من الجمعيات الأهلية من وجهة نظر المبحوثين:

أظهرت النتائج الواردة في جدول (rا ( ) أن حوالي ثلاثة

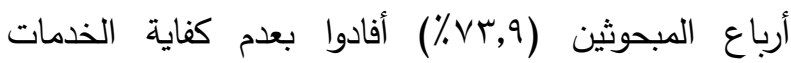

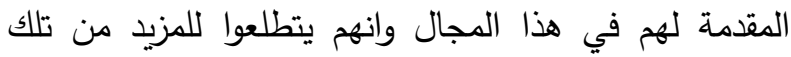

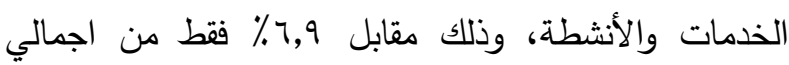
المبحوثين افادوا بكفاية تلك الخدمات.

جدول rا 1. توزيع المبحوثين وفقاً لمدى كفاية الخدمات

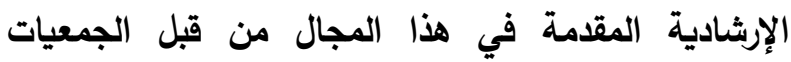

\begin{tabular}{|c|c|c|}
\hline$\%$ & التكرار & الكفاية \\
\hline 7,9 & $r$ & كافية \\
\hline $19, r$ & 09 & إلى حدا ما \\
\hline$V r, q$ & TrV & غير كافية \\
\hline $1 \ldots$ & $r \cdot V$ & الاجمالى \\
\hline
\end{tabular}

^- الطرق الإرشادية المستخدمة في تنفيذ وتقديم الأنثطة

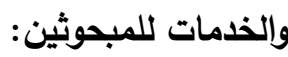

أشارت النتائج الواردة في جدول (rآ) إلى أن أكثر

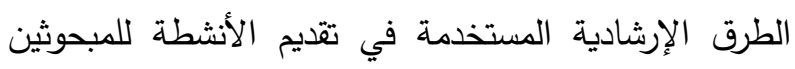
تمثلت في: عقد الاجتماعات والندوات الإرشادية، والايضاح

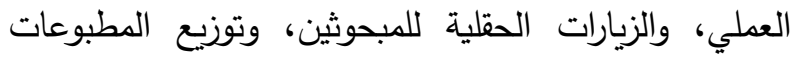

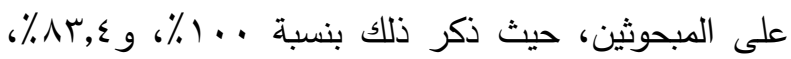

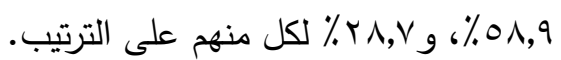


للحد من الآثار السلبية لظاهرة التغيرات المناخية، وقد ينعكس هذا ايجابياً على الاستفادة من الإن الخدمات الإرشادية المقدمة، والعمل بها وتطبيقها للحصول على منفعة أكبر.

0- الانفتاح على العالم الخارجي: أظهرت النتائج وجود علاقة ارتباطية معنوية موجبة بين الانفتاح على العالم الخارجي والاستفادة من الخدمات الإرشادية الزراعية عند مستوى معنوية ه.,.، ويمكن تفسير تلك العلاقة في ضوء أنه كلما زادت الانفتاح على العالم الخارجي والتعرض للمصادر المختلفة ومعرفة آثار تلك الظاهرة كلما زاد وعيهم بتلك الظاهرة والأضرار التي قد تتجم عن عدم العمل بالممارسات الصحيحة التي من شأنها الحد من آثار تلك الظاهرة. 7- الوعي بظاهرة التغير المناخي: أوضحت النتائج وجود علاقة ارتباطية معنوية موجبة بين الوعي بظاهرة التغير

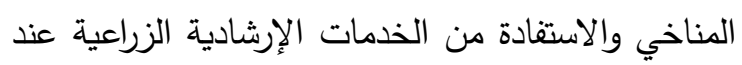
مستوى معنوية ا +,.•، ويمكن تفسير تلك العلاقة في ضوء أنه كلما زاد وعي المبحوثين بتلك الظاهرة ومسبباتها كلما زاد وعيهم بأهمية الممارسات والخدمات التي من شأنها ان تحد من الآثار السلبية التى تواجه الانتاج الزراعي بسبب تلك الظاهرة.

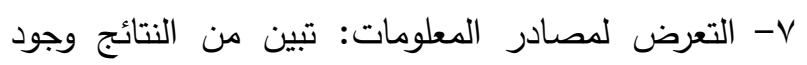

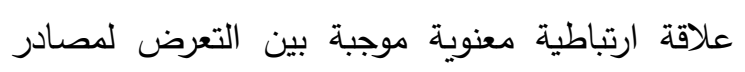
المعلومات والاستفادة من الخدمات الإرشادية الزراعية عند مستوى معنوية ا +,.•، ويمكن تفسير تلك العلاقة

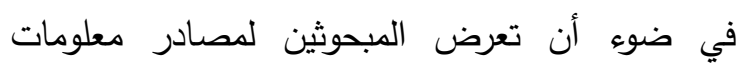
متتوعة يتيح لهم معرفة أهمية الممارسات والأنشطة الإششادية الموجهة لهم للتغلب على الآثار السلبية الناجمة عن التغير المناخي. 1- الاستفادة من مصادر المعلومات: أظهرت النتائج وجود علاقة ارتباطية معنوية موجبة بين الاستفادة من مصادر المعلومات والاستفادة من الخدمات الإرشادية الزراعية
ويمكن توضيح العلاقة الارتباطية بين مستوى استفادة المبحوثين من الخدمات الإرشادية المقدمة لهم والمتغيرات المستقلة والموضحة بجدول (ع ا ) على النحو التالي: 1- السن: أوضحت النتائج وجود علاقة ارتباطية معنوية سالبة بين السن ودرجة الاستفادة من الخدمات الإرشادية

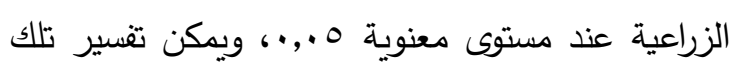
العلاقة في ضوء أن كبار السن هم أفراد تقليديون، وأكثر تمسكاً بالأفكار والممارسات القديمة، وقد لا يولون اهتماماً بمعرفة التوصيات والممارسات الجديدة وتطبيقها لتجنب حدوث التغيرات المناخية. r- المستوى التعليمي: أوضحت النتائج وجود علاقة ارتباطية معنوية موجبة بين المستوى التعليمي ودرجة الاستفادة من الخدمات الإرشادية الزراعية عند مستوى لئه

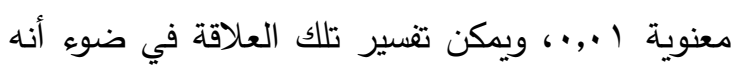
كلما زاد المستوى التعليمي كلما زادت الاستفادة من تلك فيك الخدمات، حيث تزيد فرصة الوصول إلى المصادر

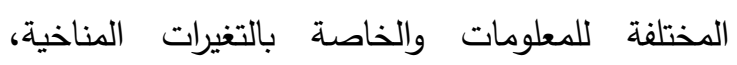
وبالتبعية زيادة الاهتمام وتطبيق الممارسات التي من لنات شأنها الحد من اثار تلك الظاهرة. r- حجم الحيازة الزراعية: أظهرت النتائج وجود علاقة ارتباطية معنوية موجبة بين حجم الحيازة الزراعية

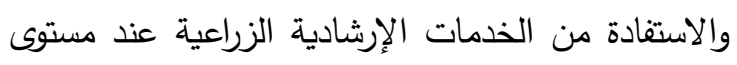
معنوية ا ب,.,، ويمكن تفسير تلك العلاقة في ضوء أنه كلما كبر حجم الحيازة الزراعية يسمح بتطبيق الممارسات الموصي بها وبالتالي زادت الاستفادة من الخدمات الإرشادية الزراعية المقدمة لهم. ع- مستوى الطموح: بينت النتائج وجود علاقة ارتباطية

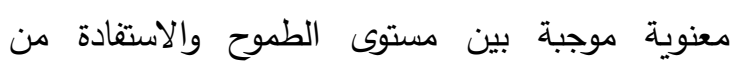

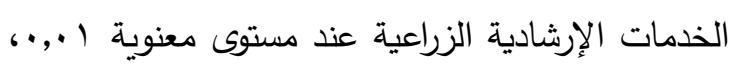
ويمكن تفنير تلك العلاقة في ضوء أن المبحوثين الذين

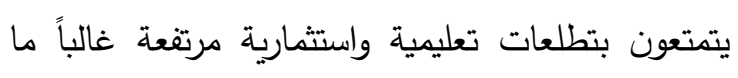
يكونوا أكثر استعداداً لمعرفة المعلومات والممارسات 
تثير نتائج التحليل الإحصائي لنموذج تحليل الإنحدار Multiple Regression Analysis Step Wise المتدرج الموضحة بالجدول (10) أن أكثر العوامل تأثيراً على درجة

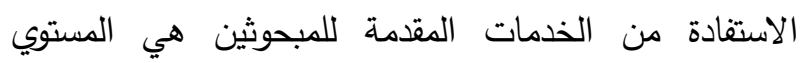

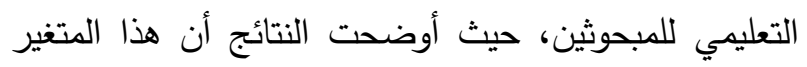

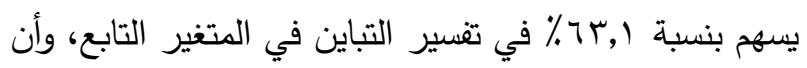

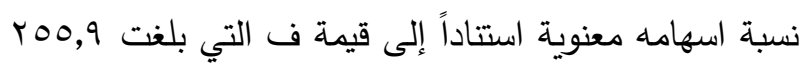
عند مستوى معنوية ا.,.، وهو ما يشير إلى ضرورة الاهتمام برفع المستوى التعليمي للمبحوثين لمواجهة تلك

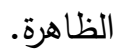

وفي المرحلة الثانية تم إدخال متغير استمرارية الخدمات الكقدمة بالإضافة إلى متغير المستوى التعليمي للمبحوثين،

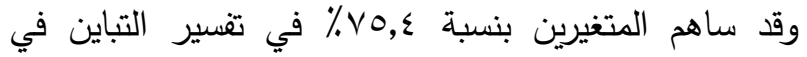

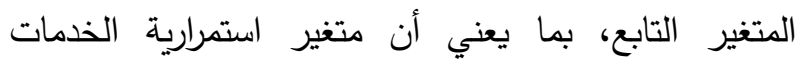
المقدمة يساهم بنسبة r, r, ٪ في تفسير هذا التباين.
عند مستوى معنوية ا.,.،، ويمكن تفسير تلك العلاقة في ضوء أن زيادة تعرض المبحوثين لكصادر المعلومات يؤثر على درجة الاستفادة من المعلومات

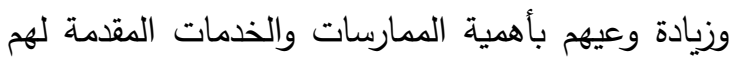
والاستفادة منها. 9- استمرارية تقديم الخدمة: أظهرت النتائج وجود علاقة ارتباطية معنوية موجبة بين استمرارية تقديم الخدمة والاستفادة من الخدمات الإرشادية الزراعية عند مستوى التئي

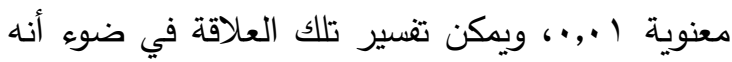
كلما تمتعت الخدمات المقدمة بالاستمرارية، كلما دل ذذلك على احتياج المبحوثين لتلك الخدمات والاستفادة منها.

• 1- العوامل المؤثرة على درجة الاستفادة من الخدمات الإرشادية المقدمة للمبحوثين من الجمعيات الأهلية الزراعية

جدول ؛ ا. العلاقة الارتباطية بين المتغيرات المستقلة ودرجة الاستفادة من الخدمات المقدمة

\begin{tabular}{|c|c|c|}
\hline (درجة الاستفادة من الخذاط البستي) & المتغيرات المستقلة & م \\
\hline *., \&OV - & السن & 1 \\
\hline$*_{*},, \vee \vee 97$ & المستوى التعليمى & r \\
\hline **, ,, O $\mathrm{r}$ & حجم الحيازة الزراعية & r \\
\hline$* *,, 741$ & مستوى الطموح & $\varepsilon$ \\
\hline$* ., T Y Y$ & الانفتاح على الكعالم الخارجى & 。 \\
\hline$* *, 7 \times 1$ & الوعي بظاهرة التغير المناخي & 7 \\
\hline$* *, \leqslant \wedge 1$ & التعرض ليصادر ألمعلومات & $\mathrm{v}$ \\
\hline$* *,, \leq 7)$ & الاستفادة من مصادر المعلومات & $\wedge$ \\
\hline$* *, \vee \vee \wedge \vee$ & استراربة تقديم الذدمة & 9 \\
\hline
\end{tabular}

جدول ه 1. نتائج تحليل الانحدار المتدرج الصاعد للعلاقة بين بعض المتغيرات المدروسة والاستفادة من الخدمات المقدمة

\begin{tabular}{|c|c|c|c|c|c|c|}
\hline قيمة ف & الانحدار & \% التراكمية للتباين & 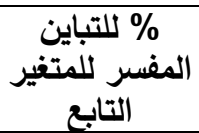 & معامل الارتباط & المتغير & 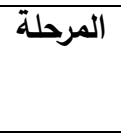 \\
\hline **Yoo, & $* * \cdot, \leqslant 9$ & $7 \pi, 1$ & - & $\cdot, \vee \vee 9$ & المستوى التعليمى & الأولى \\
\hline$* * Y Y q, \Gamma$ & $* * ;, \leqslant\rceil$ & Vo, \{ & IT,r & •, AV & استمرارية تقديم & الثانية \\
\hline
\end{tabular}




\section{المراجع}

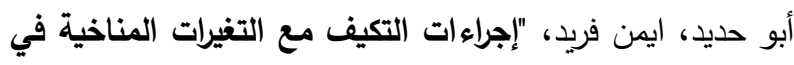

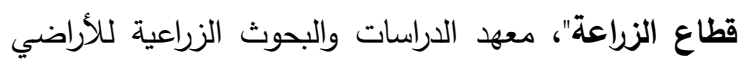

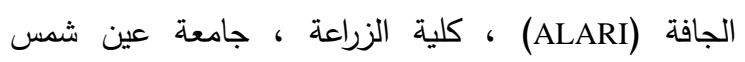

$$
\text { r. T V (ASU) }
$$

ابو حديد، ايمن فريد، "مستقبل الزراعة المصرية في ضوه البهاء

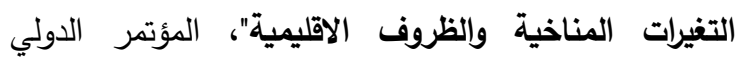

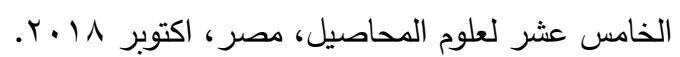
اتحاد لجان العمل الزراعي UAWC، "دليل إرشادي لآليات التكيف

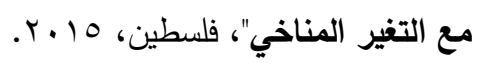

الخولي، احمد عثمان، وعزت عبد الحميد، "مشروع أساليب الحد

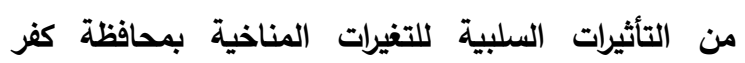
الثيخ"، الاتحاد النوعي البيئي بمصر، وزارة الدولة لثئون

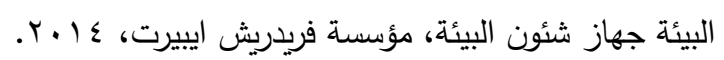
الثافعي، عماد مختار أحمد، "توظيف المنظمات غير الحكومية لئية في تقديم الخدمات الإرشادية الززاعية"، ندوة دور المنظمات الديات

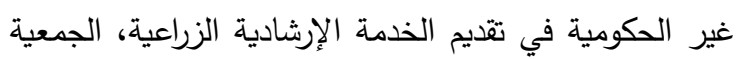

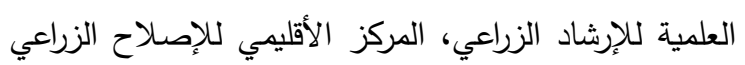
والتتمية الريفية في الثرق الأدنى CRDNE، ل . . r.

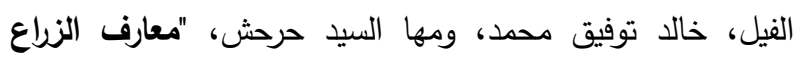

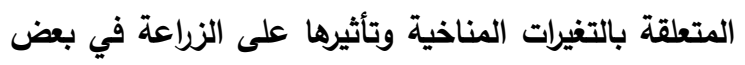

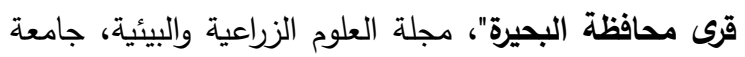

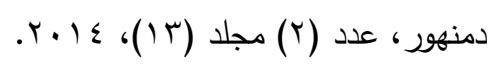
الفران، محمد أحمد، "تأثير التفيرات المناخية على الأمن الغذائي

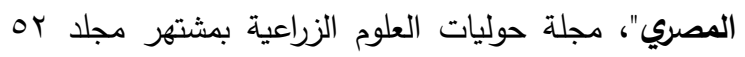

$$
\text { ( }
$$

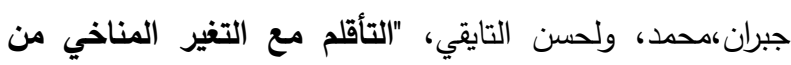

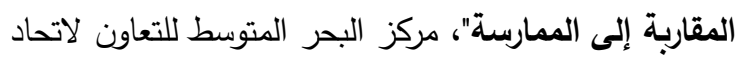

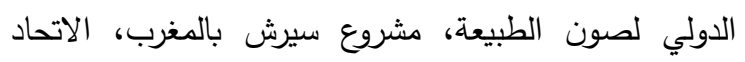

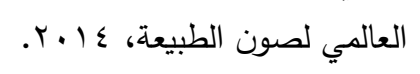

وبناءاً على ذلك أمكن رفض الفرض الاحصائي وقبول

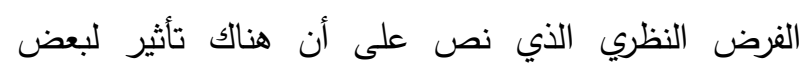

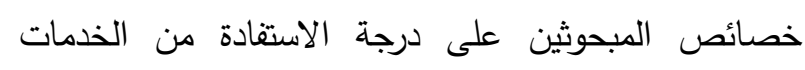

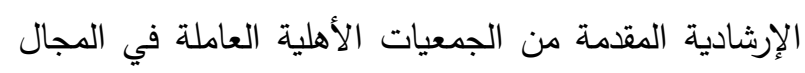
الزراعي فيما يتعلق بظاهرة التغيرات المناخية.

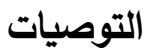

في ضوء ما أسفرت عنه نتائج الدراسة أمكن استخلاص التوصيات التالية: 1- الاهتمام بالخدمات الإرشادية الزراعية الخاصة بالإنتاج

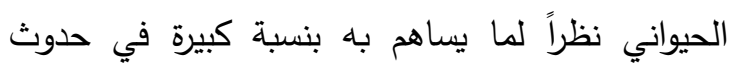

$$
\text { التغيرات المناخية. }
$$

r- العمل على رفع المستوى التعليمي للزراع، لما يساهم به

$$
\text { في التحدى لتلك الظاهرة. }
$$

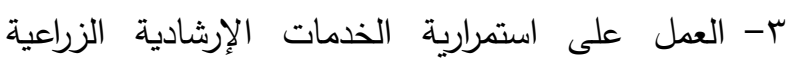

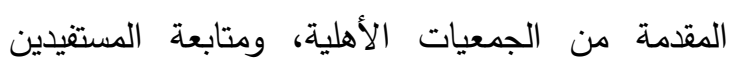

$$
\text { لتنفيذ الممارسات الموصي بها. }
$$

ع- استخدام طرق إرشادية متتوعة كالتليفونات وقناة مصر الزراعية في رفع وعي الزراع بتلك الظاهرة.

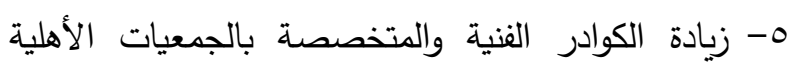

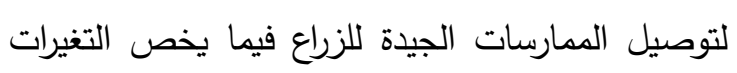
المناخية. ج- عمل لجنة تضم مختلف الجهات المعنية بتلك الظاهرة وإصدار بيانات دورية وتعريف الزراع بها بثكل دائم ومستمر - و إمراء V- إجراء المزيد من الدراسات عن دور المنظمات غير

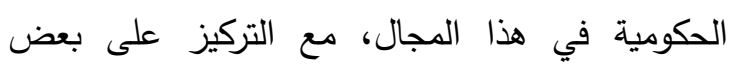

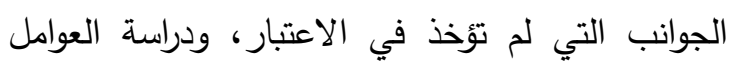
والمتغيرات التي لم تتطرق لها تلك الدراسة. 
منظمة الأغذية والزراعة للامم المتحدة FAO، "يوم الأغذية

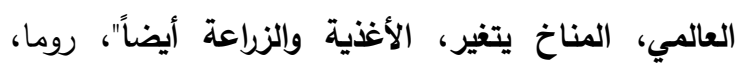
.4 .17

لجنة الزراعة، الدورة السادسة والعشرون († ب)، "تطبيق استراتيجية منظمة الأغذية والززراعة في مجال تغير المناخ، قيادة عملية

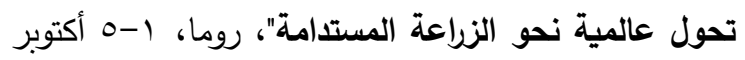
.$r \cdot 1 \Lambda$

وزارة البيئة، جمهورية مصر العربية، "تقرير حالة البيئة"، 1 ا ـ r.

Eighth International Forum OF NGOs In Official Partnership with UNESCO, "NGOs AND CLIMATE CHANGE" [Provisional title], Paris, UNESCO HQ , 7-8 December 2017.

Iwuchukwu J.C, Nwankwo O.J and Ogbonna, O.I, "Knowledge and Roles of Non Governmental Organizations (NGOs) in Climate Change Mitigation and Adaptation in Anambra State", Journal of Agricultural Extension, Vol.18 (2) December, 2014.

Kaddo, R. jameel. ," climate change: causes, effects, and solution", 2016, https:// spark.parkland.edu.

Krejcie, Robert V. and Daryle W. Morgan. "Determining Sample Size For Research Activities". Education and Psychological measurments, 30 Autumn 1970.

Lindsey Jones, Blane Harvey and Rachel GodfreyWood, "The changing role of NGOs in supporting climate services", resilience intel, Issue no. 4, September 2016, www.braced.org.

Nwankwoala , H. N. L. , "causes of climate and environmental changes, the need for environmental- friendly education policy in Nigeria", journal of education and practice, vol 6, No 30, 2015.

Sodangi I. A., Izge, A. U., and Maina, Y. T., "CLIMATE CHANGE: CAUSES AND EFFECTS ON AFRICAN AGRICULTURE", Journal of Environmental Issues and Agriculture in Developing Countries, Vol. 3, No. 3; Dec. 2011.

United States Environmental Production Agency (EPA), "climate change frequently asked questions", 2017 (www. EPA.gov).
خطاب، نجوى فؤاد، "معارف الزراع المبحوثين فيما يتعلق بظاهرة

التغير المناخي ومسبباتها وممارساتهم لمواجهة تأثيرها

الضار على الانتاج الزراعي ببعض قرى المعمورة محافظة

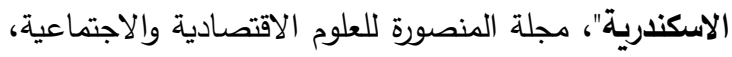

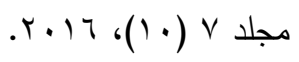

داوود، دينا حسن امام محمد، "دراسة لمستويات معارف واتجاهات

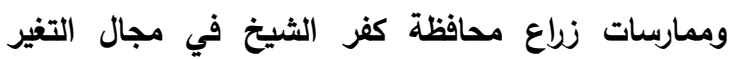

المناخي"، رسالة دكتوراه، جامعة القاهرة، كلية الزراعة،

.$r \cdot 10$

شاكر، محمد حامد زكي، "دور المنظمات غير الحكومية في

العمل الإرشادي الزراعي"، وزارة الزراعة واستصلاح

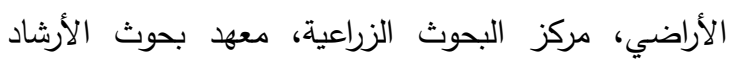

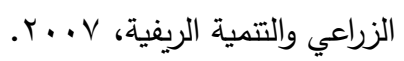

عبد الظاهر، ندى عاشور، "التغيرات المناخية وآثارها على

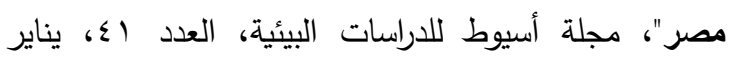

$$
. r \cdot 10
$$

عمر، ايه رشدي عبد العاطي، "دراسة وعي وإدراك المزارعين بالتغير المناخي وآثاره في ريف محافظة دمياط"، رسالة

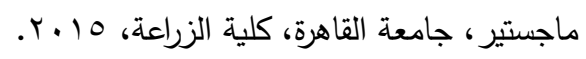

فواز ، محمود محمد، وسرحان أحمد عبد اللطيف سليمان، "دراسة اقتصادية للتغيرات المناخية وآثارها على التنمية المستدامة ودان في مصر"، المجلة المصرية للاقتصاد الزراعي، عدد يونيو

$$
.10
$$

قاسم، حازم صلاح منصور ، "إدراك واقلمة المزارعين لظاهرة تغير

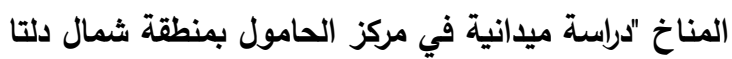

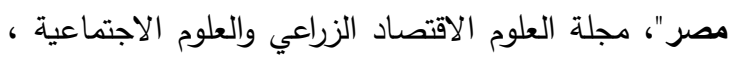

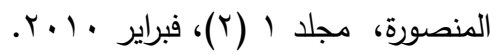

مديرية التضامن الاجتماعي بالفيوم (الاتحاد النوعي للتمية والبيئة

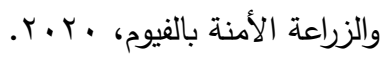

منظمة الأغذية والزراعة للامم المتحدة FAO، "حالة الأغذية

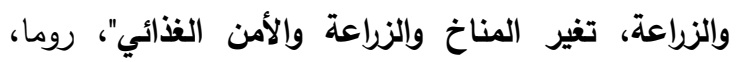


ABSTRACT

\title{
Agricultural Extension Services Provided to Farmers by Ngos in the Field of Climate Change in Fayoum Governorate
}

\author{
Salwa Mohamed Abd ElGawad Ahmed
}

The research aimed to: identify the advisory services provided by agricultural in the field of climate change, know the farmers' benefit level from these services, determine sustainability and adequacy of those services, know the information sources, identify the sustained and their adequacy of these services, Identify the most important extension methods used to aware farmers about climate change And determine the most important factors affecting of farmers' benefit level from agricultural extension services provided by those organizations in the field of climate change.

The study was conducted in Fayoum governorate. Fayoum and Tamiya destricts have been selected according to the most active NGOs in the agricultural field. Two villages were selected from each district: Damashqin and Al-Ielam from Fayoum, Kasr Rashwan and Fanos from Tamiya, A simple random sample of the beneficiaries of these associations was selected by Krejcie and Morgan equation, the sample size reached to 307 respondent.

Regarding the respondents 'awareness of the climate change findings, indicated that majority of the respondents $(68.1 \%)$ were either average or low awareness of this phenomenon, as their percentage reached $45.9 \%$ and $22.2 \%$, respectively, compared to only $31.9 \%$ of them had high awareness of this phenomenon.

finding indicated that $45.3 \%$ of respondents had average exposure information sources, compared to only $14 \%$ who had high exposure. The merchant of agricultural production supplies was the sources of information about climate change, followed by important personal experience, relatives and neighbors, NGOs, and finally the agricultural extension, as $62.2 \%$, $50.2 \%, 48.5 \%, 46.6 \%, 45.3 \%$ respectively.

findings also indicated that the level of services was average, as mentioned by $59.3 \%$.

services provided by associations to the respondents related to awareness of the causes of the phenomenon and its negative effects were: awareness of non- excessive use of pesticides, and chemical fertilizers, unburn of residues, and reduction of crops productivity, as mentioned by $78.8 \%, 71.3 \%, 57.9 \%$ and $55.4 \%$ respectively.

As for the agricultural extension services provided by these societies related to reduce the effects of climate change, it were as follows: encouraging farmers to switch to organic farming, training the respondents on making and using organic fertilizers instead of chemical fertilizers, and holding seminars to urge respondents not to pollute canals and drains and help them to its disinfection, the use of biological control of agricultural pests, and training them to recycle agricultural waste, as mentioned by $80.1 \%, 76.9 \%, 71.3 \%, 68.1 \%$ and $65.5 \%$ respectively.

About benefit level of services and activities provided to them, it was either low or average, as it mentioned by $40.1 \%$ and $38.1 \%$ respectively, compared to only $21.8 \%$ of them, their benefit was high. 